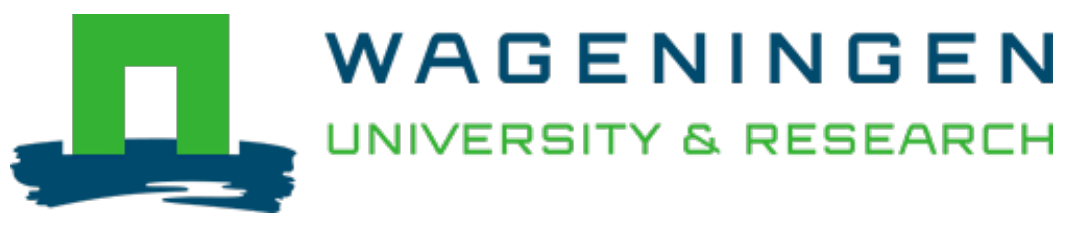

\title{
Modelling soybean and maize growth and grain yield in strip intercropping systems with different row configurations
}

\author{
Field Crops Research \\ Wu, Yushan; He, Di; Wang, Enli; Liu, Xin; Huth, Neil I. et al \\ https://doi.org/10.1016/j.fcr.2021.108122
}

This publication is made publicly available in the institutional repository of Wageningen University and Research, under the terms of article $25 \mathrm{fa}$ of the Dutch Copyright Act, also known as the Amendment Taverne. This has been done with explicit consent by the author.

Article 25 fa states that the author of a short scientific work funded either wholly or partially by Dutch public funds is entitled to make that work publicly available for no consideration following a reasonable period of time after the work was first published, provided that clear reference is made to the source of the first publication of the work.

This publication is distributed under The Association of Universities in the Netherlands (VSNU) 'Article $25 \mathrm{fa}$ implementation' project. In this project research outputs of researchers employed by Dutch Universities that comply with the legal requirements of Article $25 \mathrm{fa}$ of the Dutch Copyright Act are distributed online and free of cost or other barriers in institutional repositories. Research outputs are distributed six months after their first online publication in the original published version and with proper attribution to the source of the original publication.

You are permitted to download and use the publication for personal purposes. All rights remain with the author(s) and / or copyright owner(s) of this work. Any use of the publication or parts of it other than authorised under article $25 \mathrm{fa}$ of the Dutch Copyright act is prohibited. Wageningen University \& Research and the author(s) of this publication shall not be held responsible or liable for any damages resulting from your (re)use of this publication.

For questions regarding the public availability of this publication please contact openscience.library@wur.nl 


\title{
Modelling soybean and maize growth and grain yield in strip intercropping systems with different row configurations
}

\author{
Yushan Wu ${ }^{\text {a,b,c,1 }}$, Di He ${ }^{\text {d,1 }}$, Enli Wang ${ }^{\text {d, } *}$, Xin Liu ${ }^{a}$, Neil I. Huth ${ }^{\mathrm{e}}$, Zhigan Zhao ${ }^{\mathrm{d}}$, \\ Wanzhuo Gong ${ }^{\mathrm{f}}$, Feng Yang ${ }^{\mathrm{a}, \mathrm{b}, \mathrm{c}}$, Xiaochun Wang ${ }^{\mathrm{a}, \mathrm{b}, \mathrm{c}}$, Taiwen Yong ${ }^{\mathrm{a}, \mathrm{b}, \mathrm{c}}$, Jiang Liu ${ }^{\mathrm{a}, \mathrm{b}, \mathrm{c}}$, \\ Weiguo Liu ${ }^{\text {a,b,c }}$, Junbo Du ${ }^{\text {a,b,c }}$, Tian Pu ${ }^{\text {a,b,c }}$, Chunyan Liu ${ }^{\text {a,b,c }}$, Liang Yu ${ }^{\text {a,b,c, }}$ \\ Wopke van der Werf $^{g}$, Wenyu Yang ${ }^{\mathrm{a}, \mathrm{b}, \mathrm{c}, * *}$ \\ ${ }^{a}$ College of Agronomy, Sichuan Agricultural University, Chengdu, 611130, PR China \\ ${ }^{\mathrm{b}}$ Sichuan Engineering Research Center for Crop Strip Intercropping System, Chengdu, 611130, PR China \\ ${ }^{\mathrm{c}}$ Key Laboratory of Crop Eco-physiology and Farming System in Southwest of China, PR China \\ ${ }^{\mathrm{d}}$ CSIRO Agriculture and Food, GPO Box1700, Canberra, ACT, 2601, Australia \\ e CSIRO Agriculture and Food, GPO Box 102, 4350, Toowoomba, Australia \\ ${ }^{\mathrm{f}}$ Crop Research Institute, Chengdu Academy of Agricultural and Forestry Sciences, Chengdu, 611130, PR China \\ ${ }^{g}$ Centre for Crop Systems Analysis, P.O. Box 430, 6700 AK, Wageningen University, Wageningen, the Netherlands
}

\section{A R T I C L E I N F O}

\section{Keywords:}

Modelling

Intercropping

Light interception

APSIM

Soybean

\begin{abstract}
A B S T R A C T
Intercropping of two or more crop species increases the efficiency of resource use and often produces a greater yield per unit land area. The relative efficiency of intercropping depends on row configuration, but there is a shortage of modelling-based evaluation of alternative intercropping options due to the inadequacy of standard process-based crop models to simulate resource capture, growth and yield formation when the canopy is spatially structured in strips. We implemented a light interception model for strip crops into the APSIM Classic model and combined it with a quasi-Bayesian approach to derive the model parameters to simulate crop growth and grain yield in maize-soybean strip intercropping. We used 4 years of field data for 5 different row configurations to derive key model parameters for simulation of light interception, LAI dynamics, biomass growth and grain yield of maize and soybean intercrops. Key model parameters (e.g. RUE, $k$ etc.) were found to change with row-spacing and configuration, posing challenges to simulate different configurations with a single parameter set. The potential ranges of these key parameters were derived by constraining the model to observed data. The model can be potentially used to evaluate impact of planting configurations on productivity of strip intercropping systems, but the variability of key model parameters among configuration treatments calls for further in-depth research to improve modelling physiology of strip intercrops.
\end{abstract}

\section{Introduction}

Intercropping is defined as the cultivation of two or more crop species simultaneously in the same field (Francis, 1989). Intercropping is widely practiced across the world to increase grain production and resource use efficiency (Brooker et al., 2015; Cong et al., 2015; Mao et al., 2015; Zhang and Li, 2003; Li et al., 2020a, 2020b). Cereal-legume intercropping is one of the most common types of intercropping (Yu et al., 2015). Typically, $\mathrm{C}_{4}$ cereal crops such as maize and sorghum are the dominant plant species, whereas $\mathrm{C}_{3}$ legume crops such as beans, soybean, cowpea, groundnut, faba bean and pigeon pea are the associated or secondary species (Banik et al., 2006; Echarte et al., 2011; Fan et al., 2006; Gao et al., 2010b; Ghosh et al., 2009; Li et al., 2001). In most cereal-legume intercropping systems, the cereal species are taller than the legume, while the roots grow to a greater depth than those of legume species (Gao et al., 2010a, b). This implies that the component crops have interspecies interactions that affect aboveground light interception (Liu et al., 2017a, 2018; Liu et al., 2017b; Wu et al., 2017; Yang et al.,

\footnotetext{
* Corresponding author.

** Corresponding author at: College of Agronomy, Sichuan Agricultural University, Chengdu, 611130, PR China.

E-mail addresses: Enli.Wang@csiro.au (E. Wang), mssiyangwy@sicau.edu.cn (W. Yang).

${ }^{1}$ Equal contribution to this work
} 
2014) and belowground capture of soil water and nutrients whereby cereals are often dominant over legumes (Chen et al., 2017; Wang et al., 2017a; Yang et al., 2017; Yong et al., 2018). The complexity of interactions was often highlighted as a major reason for the difficulty to quantitatively evaluate the productivity and environmental impact of various intercropping systems (Gou et al., 2017b).

Crop modelling has become an accepted tool to assess the land productivity with different crop systems (Kirkegaard et al., 2014; Wang et al., 2008). The APSIM modeling framework (Holzworth et al., 2014; Keating et al., 2003; Wang et al., 2002) is one of the most used agricultural systems models to simulate the growth, yield and resource use efficiency of major crops (Liu et al., 2013a; Mohanty et al., 2012; Sun et al., 2016; Wang et al., 2018; Yang et al., 2013, 2015) and diverse cropping systems, including the impact of different management practices like rotations, fallowing, tillage, and grazing (Malone et al., 2007; Pembleton et al., 2013; Thorburn et al., 2001; Zeleke, 2017). APSIM has the ability to simulate crop growth and yield in intercropping systems (Carberry et al., 1996; Chimonyo et al., 2016; Dimes et al., 2011; Keating et al., 2003; Nelson and Cramb, 1998; Robertson et al., 2004; Wang et al., 2002). However, so far, only a few studies have reported using APSIM to simulate production in intercropping systems. These include a study on modelling of yield and water use efficiency of a sorghum-cowpea intercropping system (Chimonyo et al., 2016), and an application of APSIM to simulate maize-bean cropping systems in eastern and southern Africa (Dimes et al., 2011).

APSIM currently simulates intercrops by assuming a mixed canopy with a horizontally homogeneous LAI distribution (Keating and Carberry, 1993; Tsubo and Walker, 2002), which is not the case in strip intercropping. Compared with homogeneous sole crop canopy, strip intercropping creates heterogeneous canopy and thus alters radiation capture and use efficiency by varying spatio-temporal distribution of component crops (Liu et al., 2017a, 2018; Wang et al., 2015; Yang et al., 2014), particularly by changing planting configuration (row spacing, strip width, sowing densities, and sowing dates) (Gou et al., 2017b; Wang et al., 2019, 2017b; Wang et al., 2015). The current approach in APSIM for light interception of horizontally homogeneous canopy of intercrops does not consider the impact of row configurations (e.g. strip width of component crops), and therefore can't satisfactorily simulate light interception and radiation use efficiency of intercrops in strip intercropping systems. A recent study found that APSIM is not able to simulate crop growth and yield in wheat-faba bean intercropping system in Europe (Berghuijs et al., 2021).

A light interception model for strip-planted intercrops has been recently applied to study resource use efficiency of wheat-maize (Gou et al., 2017a; Wang et al., 2015; van Oort et al., 2020), wheat-cotton (Zhang et al., 2008; Mao et al., 2015), maize-soybean (Liu et al., 2017a, b) and wheat-fababean strip intercropping systems (Berghuijs et al., 2020). This model was developed based on the light interception for strip crops derived from elementary geometric principles (Goudriaan, 1977; Pronk et al., 2003). It simulates light interception of strip intercrops based on LAI, extinction coefficient (k), plant height, and strip width of component crops. Several studies have found that this model can better simulate light competition between component crops in strip intercropping systems (Liu et al., 2017a, b; Wang et al., 2015). However, due to the changes in canopy structure and interspecific interactions, the model parameters estimated for sole crops, such as radiation use efficiency (RUE) and light extinction coefficient $(k)$, may need to be re-estimated (Gou et al., 2017a, b; van Oort et al., 2020).

Up to the time of this study, no efforts was made to implement the light interception model in APSIM for simulation of strip intercrops and the APSIM model has never been tested in maize-soybean systems. APSIM is able to simulate more than 20 different crops. Implementing the light interception model for strip intercrops will extend APSIM's capability to simulate productivity and resource use efficiency of strip intercropping systems with various crops.

The main objectives of this study are to (1) implement a strip- intercrop light interception model into APSIM-Classic; (2) investigate the changes in key model parameters for light interception of intercrops and derive model parameters for simulating maize-soybean strip intercropping systems; (3) investigate the potential of using APSIM to simulate biomass and grain yield and to evaluate the impact of row space configuration in maize-soybean intercropping systems, and (4) discuss the future need for model improvement.

\section{Materials and methods}

\subsection{Field experiments}

\subsubsection{Experiment 1: maize-soybean relay strip intercropping}

A field experiment was conducted for three years from 2014 to 2016 at the experimental farm of Sichuan Agricultural University in Ya'an $\left(29^{\circ} 59^{\prime} \mathrm{N}, 103^{\circ} 00^{\prime} \mathrm{E}\right)$, Sichuan province, China. The climate is subtropical and humid, with an average annual rainfall of $1663 \mathrm{~mm}$ and a mean annual temperature of $16.5{ }^{\circ} \mathrm{C}$ (1981-2016). Daily weather data from Ya'an station, $5 \mathrm{~km}$ from the experimental site, were obtained from the National Meteorological Networks of the China Central Meteorological Agency (CMA), including daily precipitation, maximum and minimum temperature, and sunshine hours. Sunshine hours were converted to daily global radiation using the Angstrom equation (Angstrom, 1924). The soil of the experimental field is a Purple clay loam (Luvic Xerosols, FAO classification). At the beginning of experiment, total $\mathrm{N}, \mathrm{P}, \mathrm{K}$, available $\mathrm{N}, \mathrm{P}, \mathrm{K}$, and organic matter in the top $60 \mathrm{~cm}$ soil layer were $2.79 \mathrm{~g} \mathrm{~kg}^{-1}, 0.383 \mathrm{~g} \mathrm{~kg}^{-1}, 12.89 \mathrm{~g} \mathrm{~kg}^{-1}, 168.6 \mathrm{mg} \mathrm{kg}^{-1}, 81.3 \mathrm{mg} \mathrm{kg}^{-1}$, $140.1 \mathrm{mg} \mathrm{kg}^{-1}$, and $4.32 \%$, respectively.

The experiment (Experiment 1) was conducted using a randomized complete block design with three replicates. Maize and soybean were planted in alternating strips, with each strip containing two rows of the same species (soybean or maize). Row spacing between the rows of the same species (for both maize and soybean) was $0.4 \mathrm{~m}$, while the distance between maize and soybean rows was $0.6 \mathrm{~m}$ (Fig. 1). All strips were oriented north-south. Maize cultivar Zhenghong505 was sown on 29 March 2014, 2015, 2016 and harvested on 8 August 2014, 2015, 2016 Soybean cultivar Nandou12 was sown on 15 June 2014, 2015, 2016 and harvested on 25 October 2014, 2015, 2016. The planting density was 45,000 plant ha ${ }^{-1}$ for maize, and 99,000 plant ha $^{-1}$ for soybean. Fertilizer input was $270 \mathrm{~kg} \mathrm{ha}^{-1}$ of urea, $600 \mathrm{~kg} \mathrm{ha}^{-1}$ of $\mathrm{P}_{2} \mathrm{O}_{5}$ and $100 \mathrm{~kg}$ $\mathrm{ha}^{-1}$ of $\mathrm{K}_{2} \mathrm{O}$ in the sole crop and in the maize strip. The fertilizer was applied next to the maize rows. $\mathrm{P}_{2} \mathrm{O}_{5}$ and $\mathrm{K}_{2} \mathrm{O}$ were all incorporated into soil at maize sowing, while urea was applied at sowing, seeding stage and jointing stage in a ratio 2:3:5. No fertilizer was applied to the soybean strips. No irrigation was applied. Weeds, insect pests and diseases were properly controlled and the crops were managed to be not limited by other nutrients and water.

\subsubsection{Experiment 2: maize-soybean strip intercropping}

Data from a maize-soybean intercropping experiment in Shandong province were extracted from the literature (Liu et al., 2017a, 2018; Liu et al., 2017b).

The experiment was conducted for three years from 2013 to 2015 at a site in Heze City $\left(35^{\circ} 15^{\prime} 09^{\prime \prime} \mathrm{N}, 115^{\circ} 25^{\prime} 05^{\prime \prime} \mathrm{E}\right.$ ), Shandong province, China. The site is characterised by a temperate summer monsoon climate, with an average annual rainfall of $639 \mathrm{~mm}$ and average annual temperature of $14{ }^{\circ} \mathrm{C}$. The soil is a sandy loam (J-Fluvisols, FAO classification) in the upper $0.5 \mathrm{~m}$ (below $0.5 \mathrm{~m}$ is clay texture) and an available $\mathrm{N}, \mathrm{P}$ and $\mathrm{K}$ in the top soil $(0-30 \mathrm{~cm})$ of $101,34,187 \mathrm{mg} \mathrm{kg}^{-1}$, respectively. Daily weather data from Dingtao station, $60 \mathrm{~km}$ from the experimental site, were obtained from the National Meteorological Network of the China Central Meteorological Agency (CMA).

The experiment was conducted as a randomized complete block design with four intercropping treatments, each with three replicates. The treatments included maize-soybean strip intercropping (2 rows of maize intercropped with 2 rows of soybean) with three diff ;erent row 
Experiment 1

RSI (Relay strip intercropping 0.4+1.6)

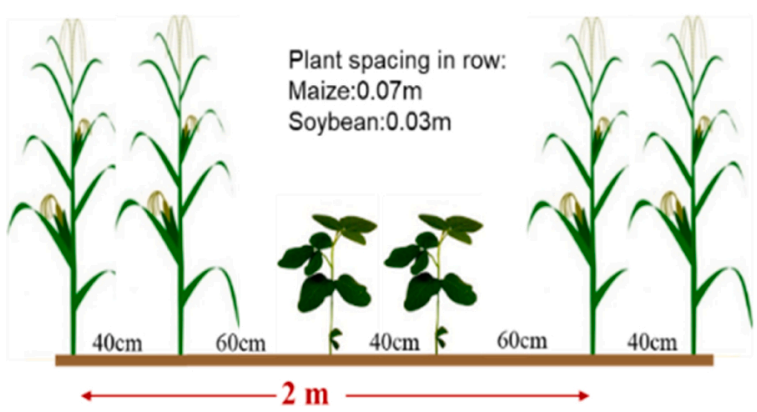

\section{Experiment 2}

\section{SI1 (Strip intercropping 0.2+1.8)}

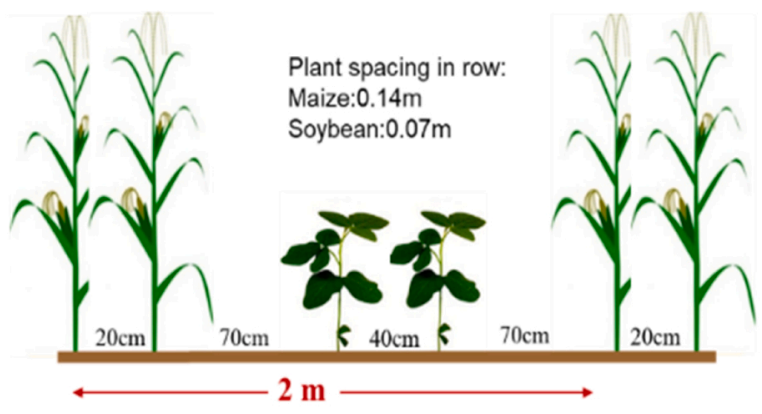

SI3 (Strip intercropping $0.6+1.4$ )

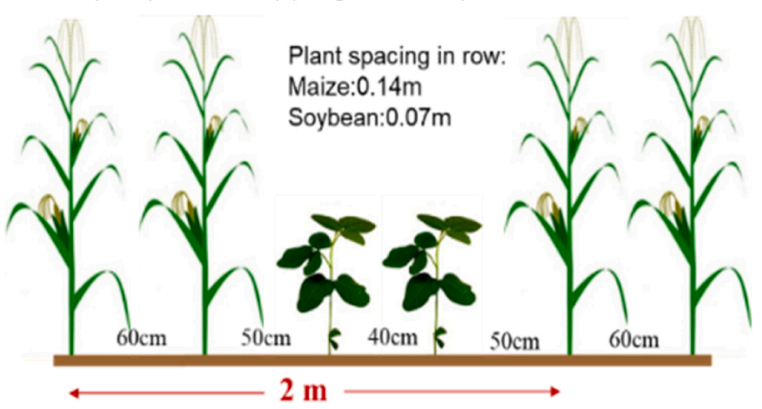

SI2 (Strip intercropping $0.4+1.6$ )

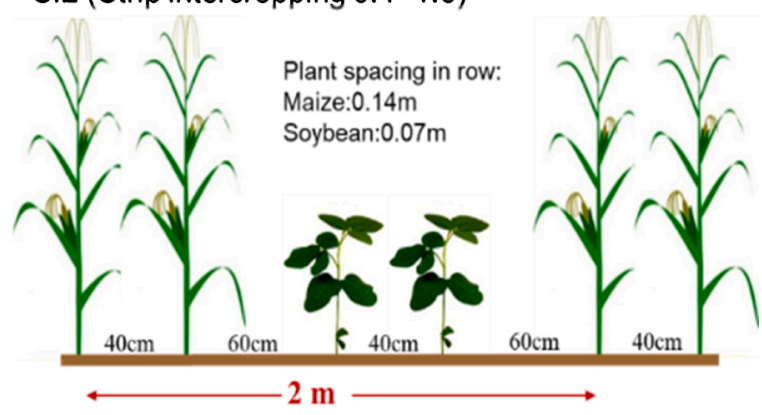

SI4 (Row intercropping 0.5+0.5)

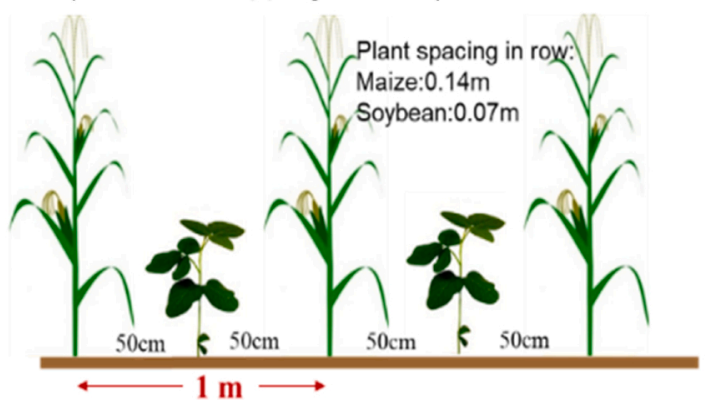

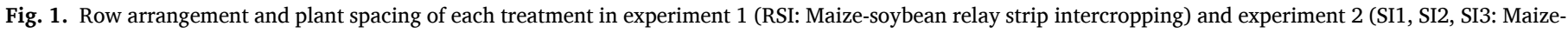
soybean strip intercropping; SI4: Maize-soybean single row intercropping).

arrangements (SI1, SI2, SI3) and maize-soybean alternate row intercropping (SI4) as depicted in Fig. 1. In SI1, maize row spacing was 20 $\mathrm{cm}$, while the distance between the neighbouring maize and soybean rows was $70 \mathrm{~cm}$. In SI2, maize row spacing was $40 \mathrm{~cm}$, while the distance between the neighbouring maize and soybean rows was $60 \mathrm{~cm}$, In SI3, maize row spacing was $60 \mathrm{~cm}$, while the distance between the neighbouring maize row and soybean rows was $50 \mathrm{~cm}$. Thus the intraspecific competition between maize rows was designed to be strongest in SI1, weaker in SI2 and weakest in SI3, while the interspecific competition between maize and soybean was expected to be weakest in SI1, stronger in SI2 and strongest in SI3. Maize and soybean yields were expected to vary as a result of the different row configurations at a constant overall density. The alternate row intercropping SI4 with an interrow distance of $50 \mathrm{~cm}$ represents the strongest interspecific interactions between maize and soybean (Fig. 1). The plant spacing within a row was $0.14 \mathrm{~m}$ for maize and $0.07 \mathrm{~m}$ for soybean, respectively. Planting density was 70,500 plant ha $\mathrm{ha}^{-1}$ for maize and 141,000 plant $\mathrm{ha}^{-1}$ for soybean, respectively.

Maize (Xuandan26) and soybean (Hedou19) were planted simultaneously in each year, i.e., on June 13, 2013, June 10, 2014 and June 14,
2015, and harvested simultaneously on September 26, 2013 and September 28, 2014 and 2015. The crops were irrigated three times (total irrigation amount $100 \mathrm{~mm}$ ) by sprinklers during the summer rainfall growing season to eliminate any water stress. Weeds and pest were properly controlled. $330 \mathrm{~kg} \mathrm{ha}^{-1}$ of urea, $100 \mathrm{~kg} \mathrm{ha}^{-1}$ of $\mathrm{P}_{2} \mathrm{O}_{5}$ and $100 \mathrm{~kg} \mathrm{ha}^{-1}$ of $\mathrm{K}_{2} \mathrm{O}$ were broadcasted in the maize strip at maize at jointing stage. No fertilizer was applied to soybean strip. Further details are provided by the original publications.

\subsubsection{Experimental data and data processing}

In both experiments, we recorded the median phenological stages of soybean (Fehr and Caviness, 1977): dates of sowing, emergence (VE), first flowering (R1), start of pod growth (R3), start of grain filling (R5), maturity (R7) and harvesting. Phenological stages of maize were recorded including dates of sowing, flowering (R1) and maturity (R6).

Five soybean plants in each plot were randomly sampled to measure leaf area, leaf number, plant height, node number on the main stem and biomass at 40,56,71,84,100, 115 days after sowing in experiment 1 and at 25, 37, 51, 66, 82, 97 days after sowing in experiment 2 . All leaves on each plant were scanned using a flatbed scanner (CanoScan 
LiDE200, Canon Inc., Japan), and the leaf area of each leaflet was determined from the images using analysis with Image J $1.45 \mathrm{~s}$. Afterwards, the leaves, petioles, and stems were separated and then dried to a constant weight at $75^{\circ} \mathrm{C}$ to determine total biomass. When soybean plants reached physiological maturity, ten consecutive soybean plants in each plot were selected to measure pod number per plant, grain number per pod and 100 - grain weight to calculate grain yield.

Five maize plants in each plot were sampled to measure leaf area, plant height and biomass at 44, 71, 78, 88, 117 days after sowing in experiment 1 and at 25, 37, 51, 66, 82, 97 days after sowing in experiment 2. Single leaf blade area of maize was calculated as leaf length $\times$ greatest leaf width $\times$ crop specific coefficient (0.70). Leaf blade and stem (including leaf sheath) were separated and dried to a constant weight at $75^{\circ} \mathrm{C}$ to determine total biomass. When maize reached physiological maturity, five maize plants were selected for yield measurement in each plot, including spike number per plant, grain number per spike and 1000-grain weight.

The total leaf area per unit area planted with a species was calculated from the experimental data by multiplying the leaf area per plant with the density of the species per unit area in the strip. Leaf area index (LAI) was calculated by dividing the total measured leaf area from the sample by the total land area covered by the sampled plants. Radiation use efficiency (RUE) was established from the empirical data by taking the ratio of accumulated dry matter and cumulative intercepted radiation (Liu et al., 2017b):

$R U E=\frac{A D M}{\sum I_{0} F}$

Here, $A D M$ was the accumulated dry matter for the whole growing period of unit land area of the maize strip or soybean strip $\left(\mathrm{g} \mathrm{m}^{-2}\right) . I_{0}$ was the daily total radiation record from the local Meteorological Bureau $\left(\mathrm{MJ} \mathrm{m}^{-2}\right)$. $F$ represents the daily fraction of intercepted PAR of the intercropped maize or soybean. $F$ was calculated using a strip crop light interception model, based on the empirical measurements (Liu et al., 2017b).

\subsection{The APSIM model and simulation of intercrops}

APSIM version 7.9 (Holzworth et al., 2014) was used to simulate phenological development, light interception, biomass growth and yield formation of maize and soybean in intercropping systems. APSIM simulates development and growth of different individual crops using a template approach (Wang et al., 2002). For both maize and soybean, APSIM uses a RUE to convert daily intercepted radiation to biomass growth rate. This potential growth rate is further reduced by suboptimal temperature and any water and nitrogen stresses. Phenological development from emergence to maturity is driven by accumulation of thermal time, with the rate of accumulation modified by photoperiod during the phase from end of the juvenile stage to floral initiation. For maize, potential LAI growth is simulated as the product of leaf number, leaf size, and number of plants per $\mathrm{m}^{2}$. Individual leaf size is calculated from final leaf number assuming that it follows a bell-shaped distribution with leaf position along the stalk. Grain yield is simulated based on grain number and grain filling rate (Archontoulis et al., 2014; Liu et al., 2013b; Zhao et al., 2015).

For soybean, a leaf-size approach together with node appearance and branching is used to simulate LAI dynamic. Node appearance depends on temperature, whilst the number of leaves on each node is determined by a branching. For grain growth, a harvest index (HI) approach is used to calculate grain biomass growth since start of grain filling (Keating et al., 2003; Robertson and Carberry, 1998; Robertson et al., 2002; Wang et al., 2002). A more detailed description of the crop models can be found at http://www.apsim.info.

APSIM is currently able to simulate intercrops that form a mixed canopy with a horizontally homogeneous LAI distribution, that is: the two canopies are completely mixed when considering the horizontal plane, though the LAI profiles over height might differ between the species, so they are not homogeneously mixed over the vertical profile. The Canopy modules in APSIM indexes all the crop species in an intercropping system and calculates the light interception of each individual species based on its LAI, height and extinction $(k)$ as weighted by the product of the light extinction coefficient $k$ and the leaf area index of all the crops (Keating and Carberry, 1993). A maximum of ten crop species can be specified for intercropping. Eqs. (2)-(4) gives an example for the fraction of light interception of two crops with the same height in a horizontally homogeneous intercrop:

$f_{\text {homo_intercrops }}=1-e^{-k_{1} L A I_{1}-k_{2} L A I_{2}}$

$f_{\text {homo_intercrop } 1}=\frac{k_{1} L A I_{1}}{k_{1} L A I_{1}+k_{2} L A I_{2}} f_{\text {homo_intercrops }}$

$f_{\text {homo_intercrop } 2}=\frac{k_{2} L A I_{2}}{k_{1} L A I_{1}+k_{2} L A I_{2}} f_{\text {homo_intercrops }}$

The Canopy module defines layer boundaries by the top of each crop canopy. Thus there are as many layers as there are crop species. Each layer in turn is taken from the top, in the combined canopy, to get the combined $(k L A I)$ value of the canopies present in that layer. The fraction of light transmitted out of the bottom of that layer in turn is the fraction entering the next layer below. The total radiation intercepted in a layer is divided amongst the canopies occupying the layer, being done on the basis of the product $k$ LAI of each species' canopy (Eqs. (2) and (4)). LAI is assumed to follow a power function with relative height (Eq. (5)):

$L A I(h)=h^{0.5}$

where $h$ is the relative height ( 0 at the bottom and 1 at the top of the canopy). Accordingly, $47 \%$ of the leaf area is in the top $10 \%$ of height, $27 \%$ in the next $10 \%, 15 \%$ in the next $10 \%$, and so on (http://www. apsim.info).

The Canopy module within APSIM has been successfully used in the study of crop-weed competition (Wiles and Wilkerson, 1991) and intercropping systems (Keating and Carberry, 1993). However, when applied to strip intercropping systems, the algorithms in the Canopy module overestimate the light interception of the taller crop species and underestimate the light interception of the lower species (Gou et al., 2017b).

\subsection{Light interception model for strip intercrops and its implementation in APSIM}

We integrated a strip intercrop light interception model into APSIM to test how it improves simulations of canopy development, biomass growth and yield of maize and soybean in strip intercropping systems with varying row configurations. The new model was based on the algorithms originally developed by Goudriaan (1977) and Pronk et al. (2003) for simulation of light interception of strip-planted sole crop, which was further modified/enhanced for application to strip intercrops by Zhang et al. (2008); Mao et al. (2015); Wang et al. (2015) and Gou et al. (2017a). It simulates light distribution of intercrops as a function of strip widths, LAI and heights of two crops, in which crop LAI and height change dynamically over time. A short summary of the light interception model for strip-planted intercrops is given in Appendix 1.

To implement the model, we modified the Canopy module to let it read three extra parameters (StripIntercropping $=$ true/false, StripWidth, and PathWidth). If StripIntercropping is true, the strip intercropping light interception model is used to calculate the light interception of two crops based on their heights together with strip width (StripWidth), and path width (PathWidth as strip width of the second crop). No other changes were made in the code. 


\subsection{APSIM parameterization and testing}

The soybean data from Experiment 1 and maize data from Experiment 2 SI2 were initially used to derive the APSIM parameters for the crop cultivars used in the experiments. The purpose of this study is to investigate whether APSIM with the light interception model for strip intercropping is able to simulate the growth and yield of the two species in strip intercropping with different row configurations. In order to reduce uncertainties caused by simulation of phenological stages, we firstly derived the phenological parameters for the local maize and soybean cultivars using a trial-and-error method to minimize the RMSE between observed and simulated dates of flowering and physiological maturity.

For soybean, previous studies indicate that organ sizes, leaf/node appearance rate and radiation use efficiency under intercropping change significantly as compared to sole crops (Liu et al., 2017a; Li et al., 2020b). Comparison to the observed data from Experiment 1 showed smaller individual leaf sizes, longer node phyllochron and higher RUE (Appendix 2 Fig. A1). We used these observed values to replace the default values in APSIM. In addition, we modified the thermal time to senesce one node of soybean from 68 (APSIM default) to 100 (relay strip intercropping) and to 120 (strip intercropping) to ensure soybean can mature before all leaves become senesced.

For maize, the leaf size profile was modified based on data for maize cultivars in China Zhen et al. (2018) (Appendix 2 Fig. A2). Specific leaf area, extinction coefficient, radiation use efficiency and plant height from Experiment 2 SI2 (Appendix 2 Fig. A2) were used for simulating maize in strip intercropping.

With the above parameterisation, we ran APSIM to see how it performs in terms of simulating the dynamics of LAI and biomass, and grain yield for soybean and maize in strip-intercropping systems.

\subsection{Parameter optimisation}

Due to the uncertainties in several model parameters (present in Appendix 2 Figs. A1, A2), we further applied an quasi-Bayesian optimisation method (Luo et al., 2015) to constrain model simulations to measured data of LAI dynamic, biomass and yield of the two crops in all treatments and derive the likely distributions of key parameters for each treatment in order to improve the simulations of maize and soybean in strip intercropping. We did this optimisation separately for each configuration treatment. These parameters include RUE, extinction coefficient, specific leaf area, height-stem weight relationship, leaf senesce rate (maize), thermal time to senesce one node (soybean) and grain growth parameters (maize). Each parameter was first assumed to exhibit a uniform distribution bounded within a range (Figs. 2 and 3). The ranges of parameter values were confined to values determined to be biologically and physically possible based on prior knowledge and results (Yang et al., 2014, 2017; Liu et al., 2018, 2017b). We used the normalized root mean square error (NRMSE) as goodness of fit criteria to be optimized in the Bayesian calibration. This metric was calculated as follows:

$R M S E=\sqrt{\frac{\sum_{i=1}^{n}\left(Y_{i}-X_{i}\right)^{2}}{\mathrm{n}}}$

$N R M S E=\sqrt{\frac{\sum_{i=1}^{n}\left(Y_{i}-X_{i}\right)^{2}}{\mathrm{n}}} / M$
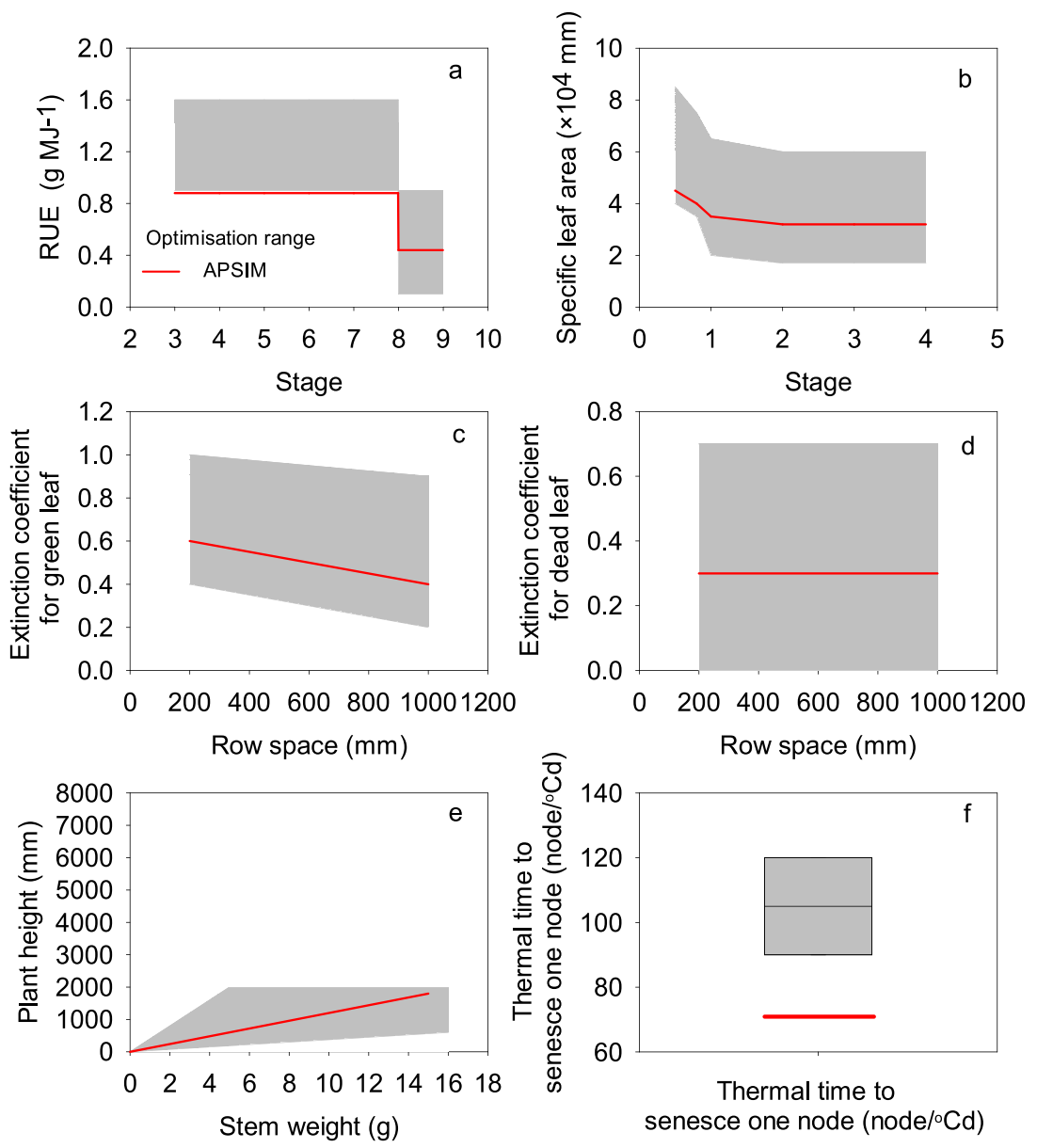

Fig. 2. Prior distribution for optimisation for soybean. a: RUE, b: specific leaf area, c: extinction coefficient for green leaf, d: extinction coefficient for dead leaf, e: plant height vs stem weight, f: thermal time to senesce one node. Red line represent the default value in APSIM, grey zone represent the distribution range based on prior knowledge. black lines in $g$ represent the average value of the distribution range box (For interpretation of the references to colour in this figure legend, the reader is referred to the web version of this article.). 

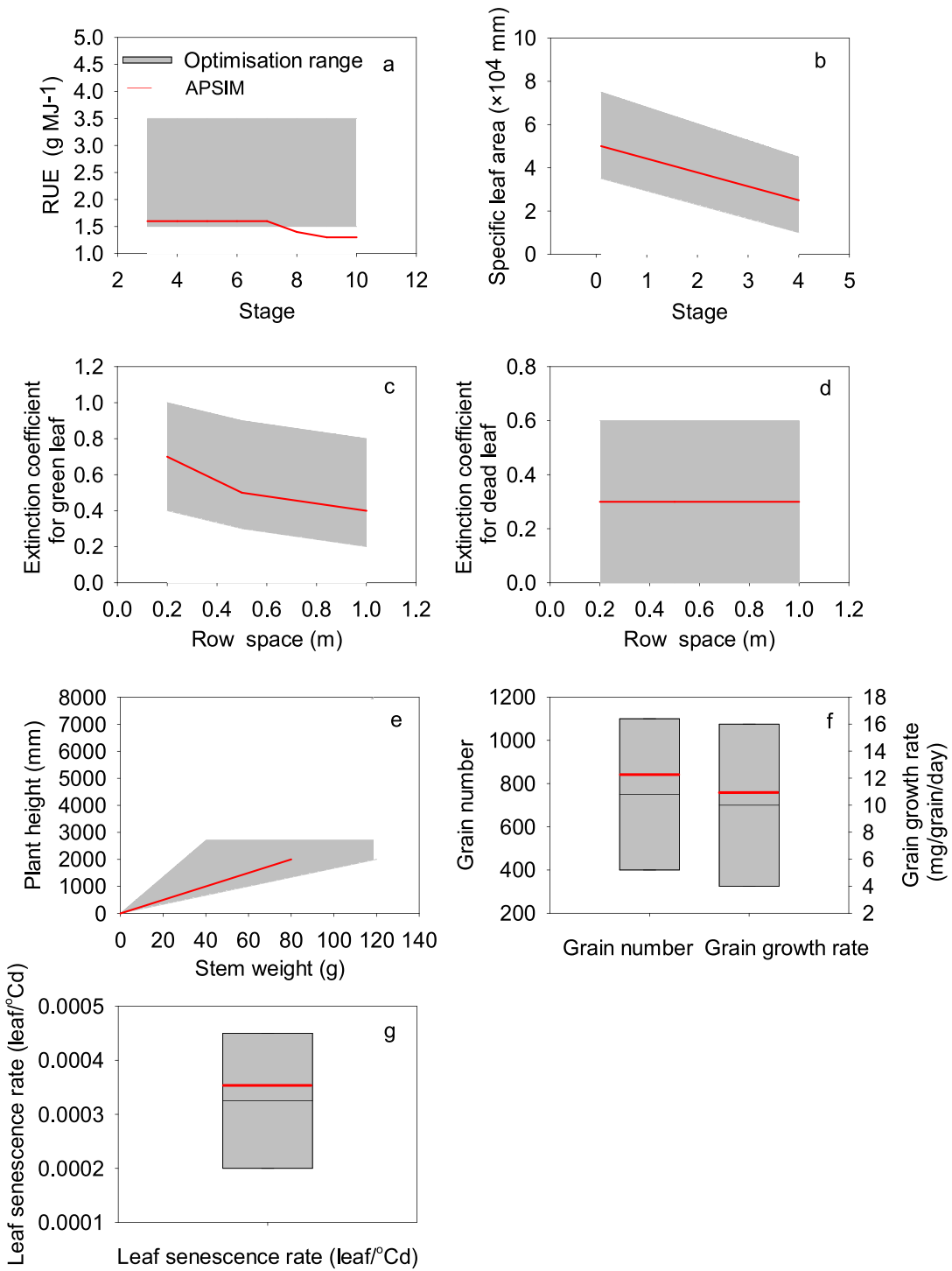

Where $X_{i}$ and $Y_{i}$ are the paired observed and simulated values. $M$ is the average of the observed values, and $n$ is the number of observations.

In order to assess the impact of equifinality, i.e. multiple combinations of parameters that resulted in similar model performance $\mathrm{He}$ et al., 2017) and the likely change in model parameters caused by intercrop configurations, we defined criteria to select an ensemble of parameters that resulted in NRMSEs between observed and simulated LAI, biomass, yield less than a certain value respectively. For maize, we targeted to constrain the model to observed LAI dynamics, maximum biomass and yield with a NRMSE less than $30 \%, 15 \%$ and $15 \%$, respectively. For soybean, the model was constrained to LAI dynamics, biomass dynamics and grain yield with a NRMSE less than $30 \%, 30 \%$ and $15 \%$, respectively. The determination of these criteria took into account of the availability and importance of observed data as well as what is achievable with the model and data. LAI dynamics was considered to be essential for light interception of both crops. Optimising against the observed biomass dynamics of the shorter crop soybean further constrained the space of parameters affecting biomass growth, $i$. e., RUE and $k$.

In addition, we choose one set of model parameters from the above ensemble as the 'best 'parameter set that enable best simulation of final biomass and grain yield of both crops. This is the parameter combinations that led to the least combined NRMSE (NRMSEc) between
Fig. 3. Prior distribution for optimisation for maize. a: RUE, b: specific leaf area, c: extinction coefficient for green leaf, d: extinction coefficient for dead leaf, e: plant height vs stem weight, f: grain number and grain growth rate, g: leaf senescence rate. Red line represent the default value in APSIM, grey zone represent the distribution range based on prior knowledge, black lines in $\mathrm{f}$ represent the average value of each distribution range box (For interpretation of the references to colour in this figure legend, the reader is referred to the web version of this article.). observed and simulated biomass and yield of both crops. NRMSEc is calculated as:

$N R M S E c=\frac{1}{4}\left(N R M S E_{m b}+N R M S E_{m y}+N R M S E_{s b}+N R M S_{s y}\right)$

Where $N R M S E_{m b}$ and $N R M S E_{m y}$ represent the NRMSEs for maximum aboveground biomass and yield of maize, while $N R M S E_{s b}$ and $N R M S E_{s y}$ that of soybean.

\section{Results}

\subsection{Light interception of strip intercrops}

First, we compared the effect of row and strip configuration on the light interception by the taller crop species (maize) and the lower crop species (soybean). The fraction of light interception was calculated using the light interception model for horizontally homogeneous intercrops (HIC, the default model in APSIM) and for strip-intercrops (SIC, the new model) under four different row spacing arrangements (SI1, SI2, SI3, SI4), assuming simultaneous maize and soybean intercrops with a growth duration of 120 days, maximum LAI of 5 for maize and 3 for soybean, and a maximum crop height of $2.5 \mathrm{~m}$ for maize and $0.8 \mathrm{~m}$ for soybean. 
As shown in Fig. 4, in the intercrop treatments SI1, SI2 and SI3, the light interception model for strip-intercrops (SIC) calculated a lower fraction of light interception by the higher crop (maize) and a higher fraction by the shorter crop (soybean), than the HIC model. Thus, if the HIC model was used for strip intercrops, it would overestimate the fraction of light interception by the taller crop species and underestimate the fraction of light interception by the lower crop species. In addition, from SI1 to SI3, the maize row spacing was increasing from 20 $\mathrm{cm}$ to $60 \mathrm{~cm}$ and the distance between the neighbouring maize and soybean rows was decreasing from $70 \mathrm{~cm}$ to $50 \mathrm{~cm}$, leading to changes in the crop strip width of both crops. With the SIC model, the light interception of maize was increasing with wider distance in maize while the light interception of soybean was decreasing with narrow distance from soybean to maize in SI1 to SI3. The HIC model does not capture this difference because it assumes a horizontally homogeneous canopy, and its algorithms do not consider the impact of changing space between crops.

\subsection{Model performance with derived parameters based on experimental data}

With the strip-intercrop (SIC) light interception model and the values of parameters derived using the experimental data (the blue line in Appendix 2 Figs. A1, A2), APSIM was unable to accurately simulate the growth of soybean and maize in strip intercropping systems with different row configurations (Fig. 5). There was an underestimation of maize LAI and biomass, but a tendency to overestimate soybean LAI, biomass (when the observed max LAI was greater than 3 ) and grain yield.

\subsection{Ranges of parameter values derived from optimisation}

The wide distributions of the parameter values clearly show equifinality (Figs. 6 and 7). For soybean (Fig. 6), the derived RUE for pregrain filling ranges from 1.1 to $1.6 \mathrm{~g} \mathrm{MJ}^{-1}$, with the average value in all treatments much higher than the APSIM default value of $0.88 \mathrm{~g} \mathrm{MJ}^{-1}$. However, the average RUE across treatments is close to $1.27 \mathrm{~g} \mathrm{MJ}^{-1}$, similar to the value obtained from experiment (Appendix 2 Fig. A1 e). This indicated that the derived values from optimisation agree with the actual values from experiment. Except for SI1, the results also seem to indicate that a higher RUE before grain filling and a lower extinction coefficient for green leaf area (e.g. from SI1 to SI4) are needed to simulate the soybean biomass growth when it is more enclosed by the maize canopy (Fig. 6a, c). This may be explained by the reduction in radiation intensity and the increase in diffuse radiation when soybean is more shaded, but requires further data to verify, though the increase in specific leaf area (Fig. 6e) also support this reasoning. The relatively higher RUE for SI1 may be caused by the underestimation of LAI (Fig. 8). In addition, the thermal time to senesce one node $\left(116.6{ }^{\circ} \mathrm{C} \mathrm{d} /\right.$ node $)$ is much higher than that of APSIM default value (68) (Fig. $6 \mathrm{~h}$ ).

For maize (Fig. 7), all the derived RUE values (1.5-3.5 $\mathrm{g} \mathrm{MJ}^{-1}$ ) for pre-grain filling are higher than the APSIM default (1.6), with an average value for RUE is $2.47 \mathrm{~g} \mathrm{MJ}^{-1}$, close to the value obtained from the experiment (Appendix 2 Fig. A2 e). This indicated that the derived values from optimisation agree with the actual values from experiment. The extinction coefficient for dead leaf varied over the range of $0.18-0.60$, higher than the default values in APSIM (0.1). The ranges of variation, median and the mean values in stem weight, head number and grain growth rate are similar across different treatments (Fig. 7 h, f, e), indicating little change in those parameters for maize between the treatments. The mean value of leaf senescence rate in five treatment $\left(0.00024\right.$ leaf $\left./{ }^{\circ} \mathrm{Cd}\right)$ is much lower than that of APSIM default value $\left(0.00035\right.$ leaf $\left./{ }^{\circ} \mathrm{Cd}\right)$ (Fig. 7 j). This is reasonable considering the staygreen nature of the modern cultivar. In general, the mean/median values of all parameters for maize differ less between treatments than those of soybean, likely due to the higher crop canopy of maize which is less affected by the lower crop soybean.

\subsection{Simulation of LAI and biomass dynamics}

Figs. 8 and 9 summarises the comparison of simulated and observed LAI, biomass and yield dynamics in all three years. Simulations were generated using the 'best' parameter set for each treatment (lines) and with the multiple sets of parameters (the ensembles) from Figs. 6 and 7
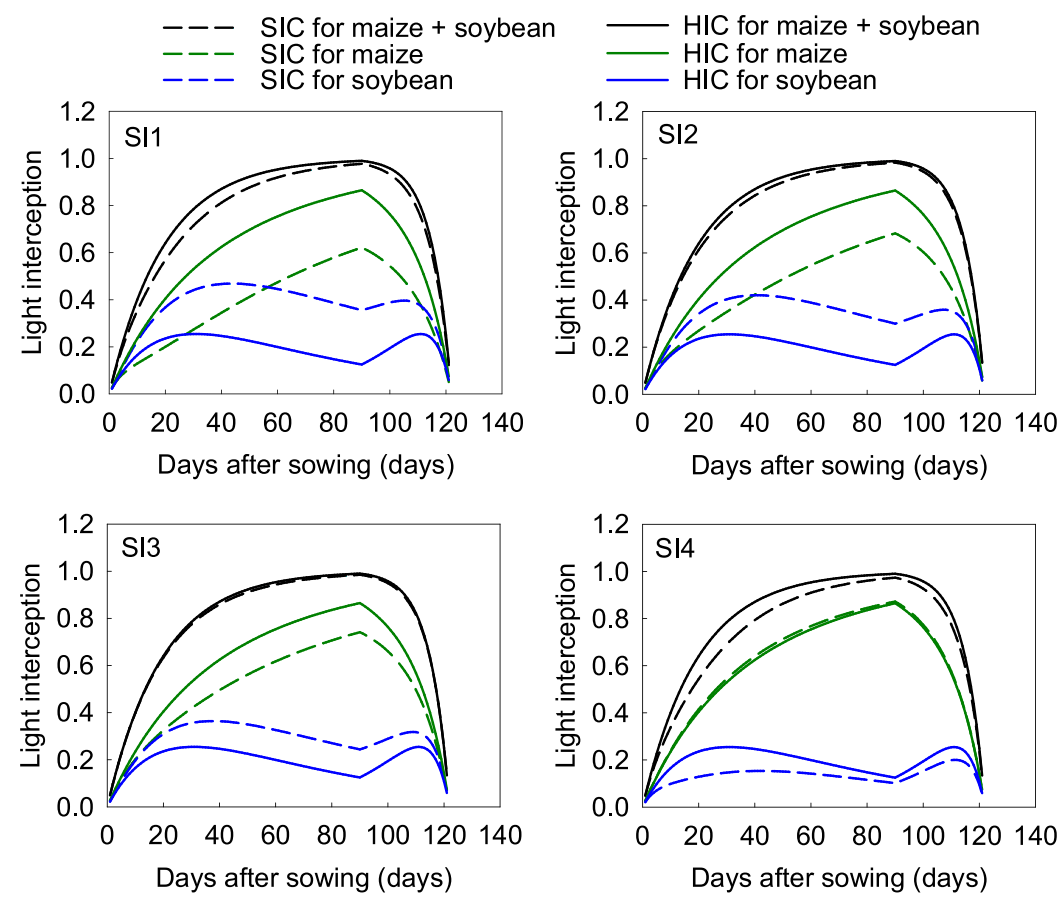

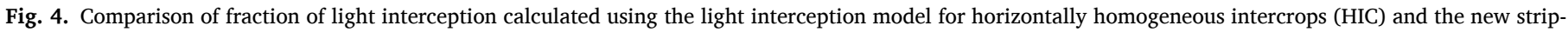
intercrop model (SIC) for four different row spacing arrangements in Experiment 2 (SI1, SI2, SI3, SI4 see Fig. 1). 
LAI
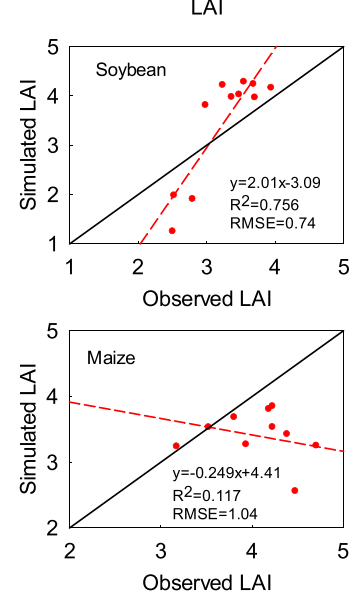

Biomass
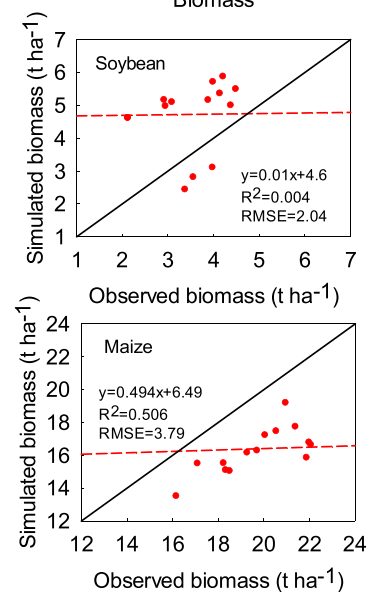

Yield
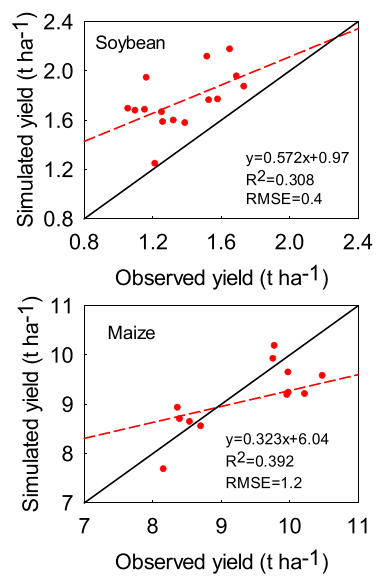

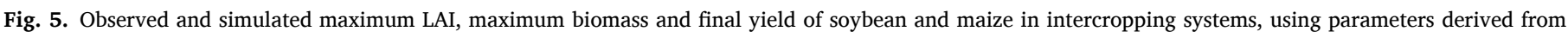
experimental data.
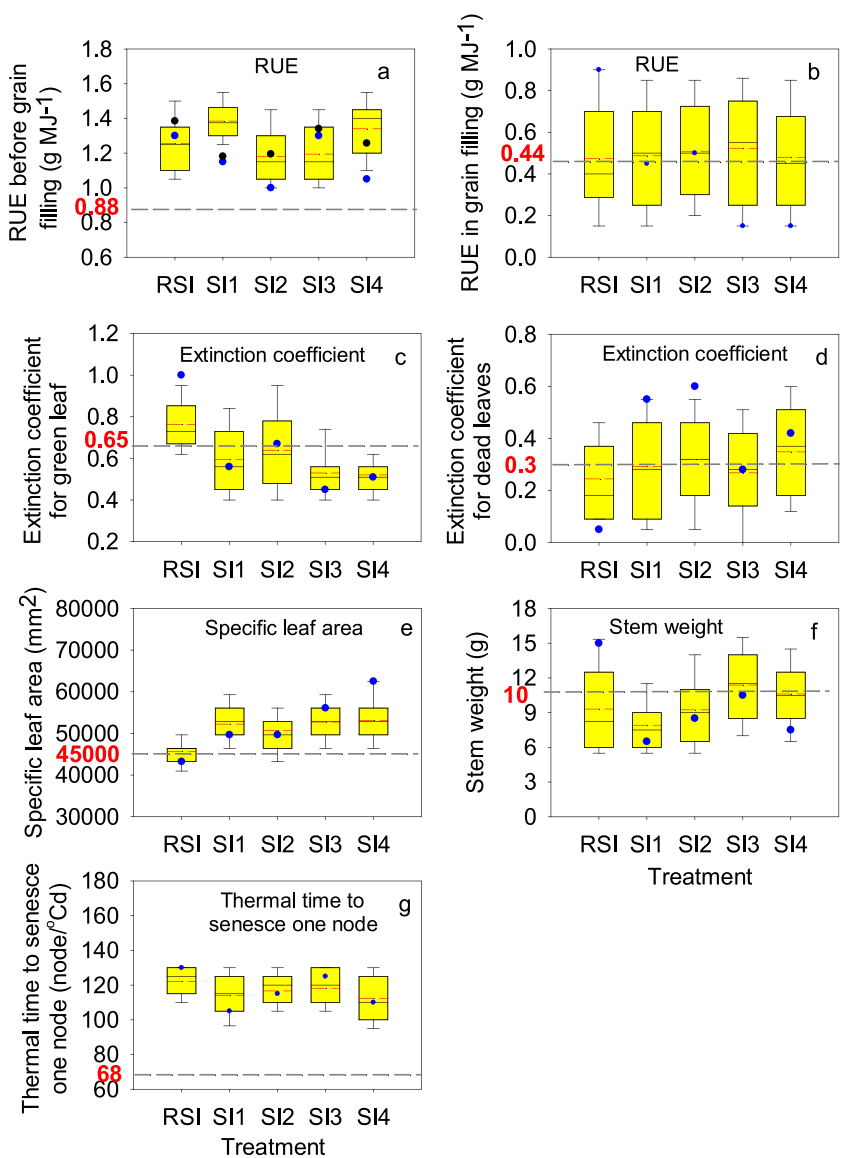

Fig. 6. Posteriori distribution of APSIM parameters for soybean, estimated by quasi-Bayesian calibration for four different intercropping treatments. Panels show the posteriori distribution of values of RUE before grain filling (a) and in grain filling (b), extinction coefficient (c, d), specific leaf area (e), stem weight per unit stem length (f), and thermal time to senesce one node ( $g$ ). The yellow boxes show the 25, 50, and 75 percentiles of the distribution of parameter values, the whiskers indicate the 10 and 90 percentiles, and the red dashed horizontal lines show the average value of quasi-Bayesian calibration. The black circles in (a) show the value obtained from experiment 2 . The blue circles show the parameters that led to the smallest NRMSE between observations and simulations. The grey dash line show the default value from APSIM (For interpretation of the references to colour in this figure legend, the reader is referred to the web version of this article.). (the cyan area). The Appendix 2 Figs. B1, B2 also provides the comparisons of the observed and simulated LAI and biomass dynamics and grain yield for each year. For both crop species, the results show great variability in simulated biomass and yield, characterised by the much wider regions of simulated values (cyan region), which was caused by variations in model parameters. For both maize and soybean, the 'best' parameter set enabled a generally good match between simulated (lines) and observed LAI, biomass and yield (dots). However, even with the 'best' parameter set, the model was not able to simulate some treatments well (e.g. soybean LAI in RSI \& SI1 and biomass in SI3) due to the fact that the model does not fully capture the complex interactions between the two species caused by their different growth dynamics and the subsequent change in the microclimate.

\subsection{Simulation of final biomass and yield across treatments}

Based on the derived parameter distributions, the simulated ranges of final biomass and yield for maize and soybean are shown in Fig. 10. For soybean, the 'best' parameter set enabled the model to capture 76.6 $\%$ and $78.9 \%$ of the variation in observed biomass and yield, respectively, with corresponding NRMSE of $8.7 \%$ and $7.9 \%$. For maize, the model simulated final biomass and yield with NRMSE less than $10 \%$ with the 'best' parameter set. Maize yields in the treatments SI1, SI2, SI3, SI4 in 2014 seem to be underestimated, but this could well be due the higher measured yield in 2014 than the other two years (with similar final biomass), with unknown causes and potential measurement inconsistency. But for the overall performance, the model simulated the final biomass and yield for intercrops with acceptable accuracy with the derived parameters.

\section{Discussion}

\subsection{Modelling strip intercrops}

This was the first attempt to integrate a strip-intercrop light interception model into APSIM, with the aim to evaluate how planting configurations influence light interception, plant growth and grain yield in strip intercropping. The new model contrasts to the existing models that assume a horizontally homogeneous canopy (HIC) for simulation of light interception of intercrops e.g., the crop-weed competition model INTERCOM (Baumann et al., 2002; Kropff and Van Laar, 1993), the homogeneous mixing model STICS (Corre-Hellou et al., 2009), the cereal-legume mixture model (Tsubo et al., 2005), and the default model in APSIM. It has been previously found to more accurately simulate light interception in several strip intercropping systems (Tan et al., 2020; van 

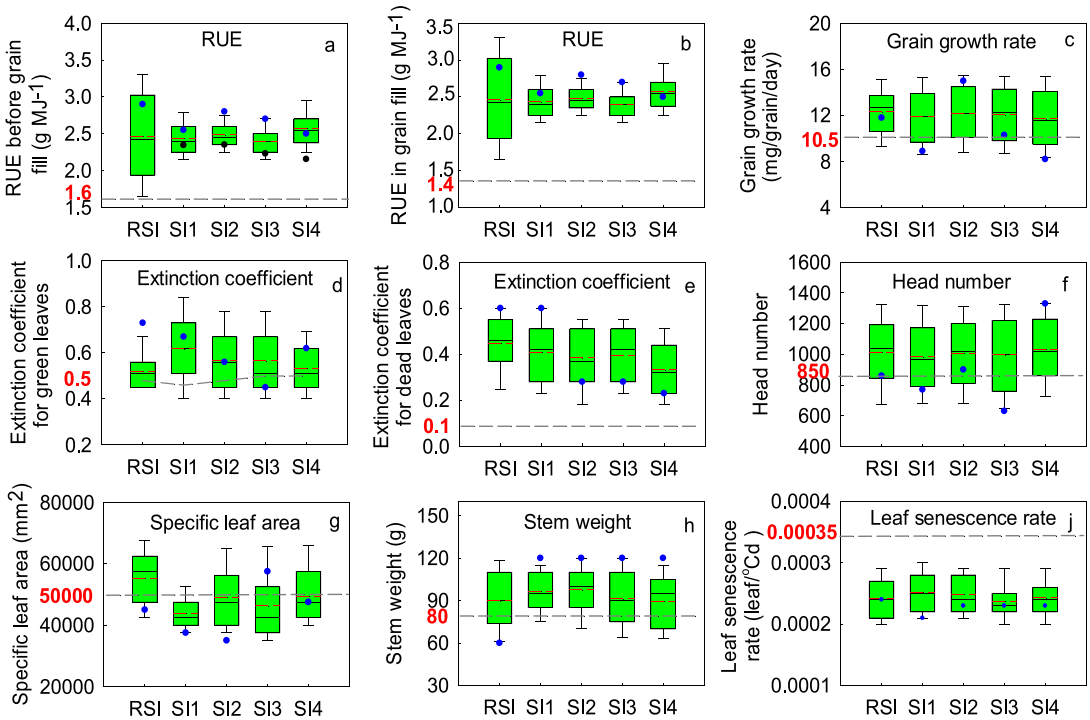

Fig. 7. Posteriori distribution of APSIM parameters for maize, estimated by quasi-Bayesian calibration for data in four intercropping treatments. Panels show the posteriori distribution of values of the RUE before grain filling (a) and in grain filling (b), grain growth rate (c), extinction coefficient (d, e), head number (f), specific leaf area (g), stem weight per unit height (h) and leaf senescence rate (j). The green boxes show the 25,50 , and 75 percentiles of the distribution of parameter values, the whiskers indicate the 10 and 90 percentiles, and the red dashed horizontal lines show the average value of quasi-Bayesian calibration. The black circles in (a) show the value obtained from experiment 2 . The blue circles show the parameters that led to the smallest NRMSE between observations and simulations. The grey dash line show the default value from APSIM (For interpretation of the references to colour in this figure legend, the reader is referred to the web version of this article.).
$\mathrm{LAI}$
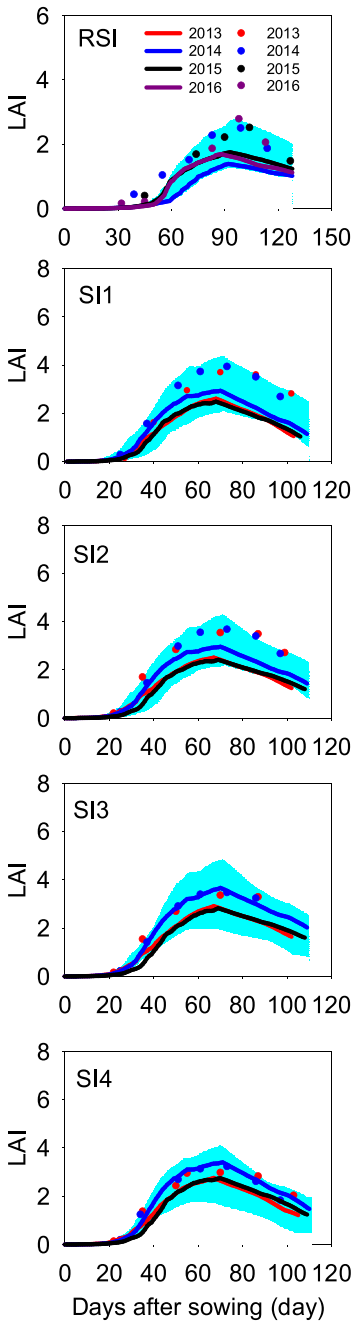

Biomass
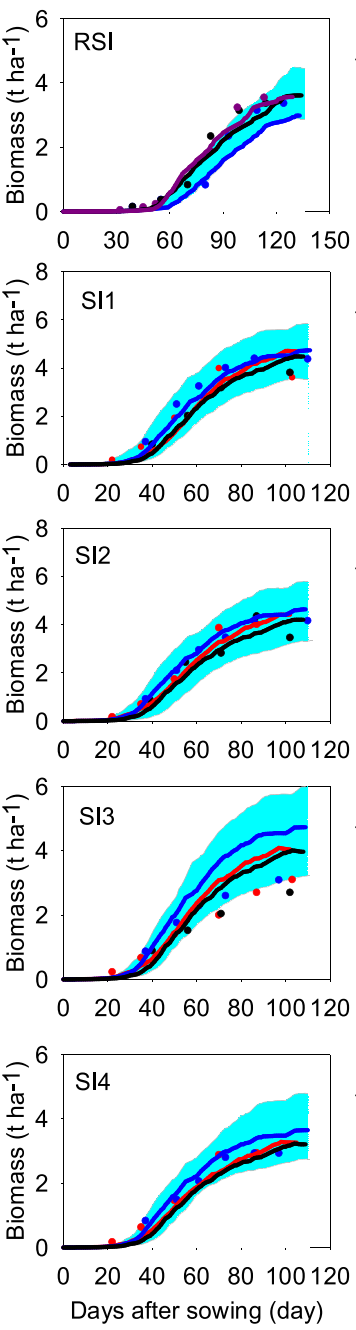
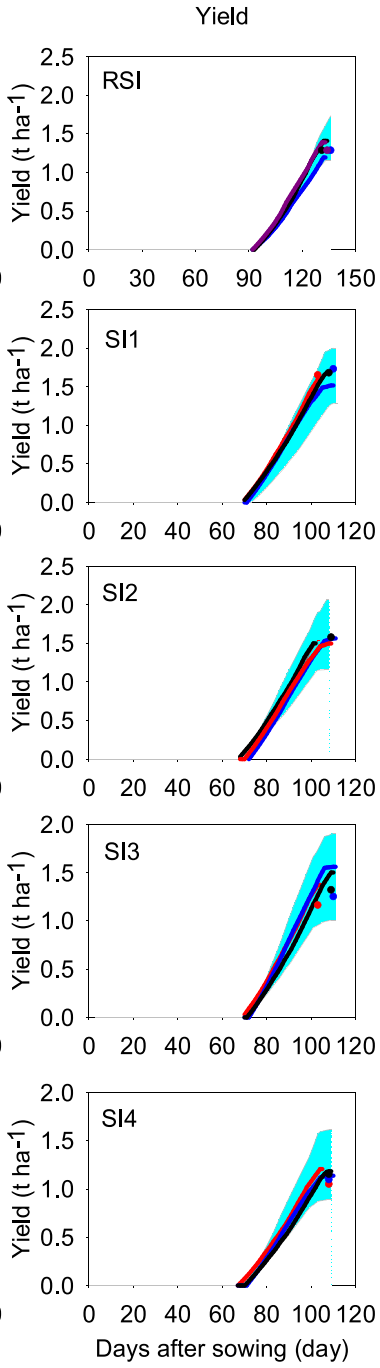

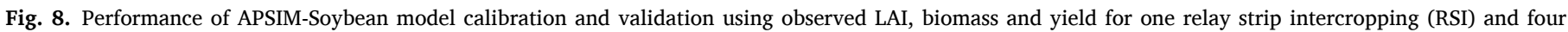

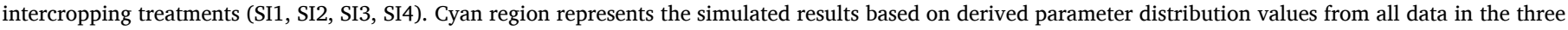

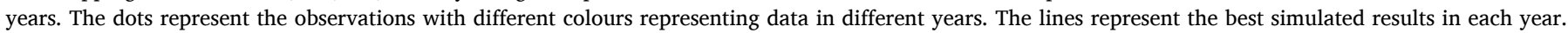


LAI
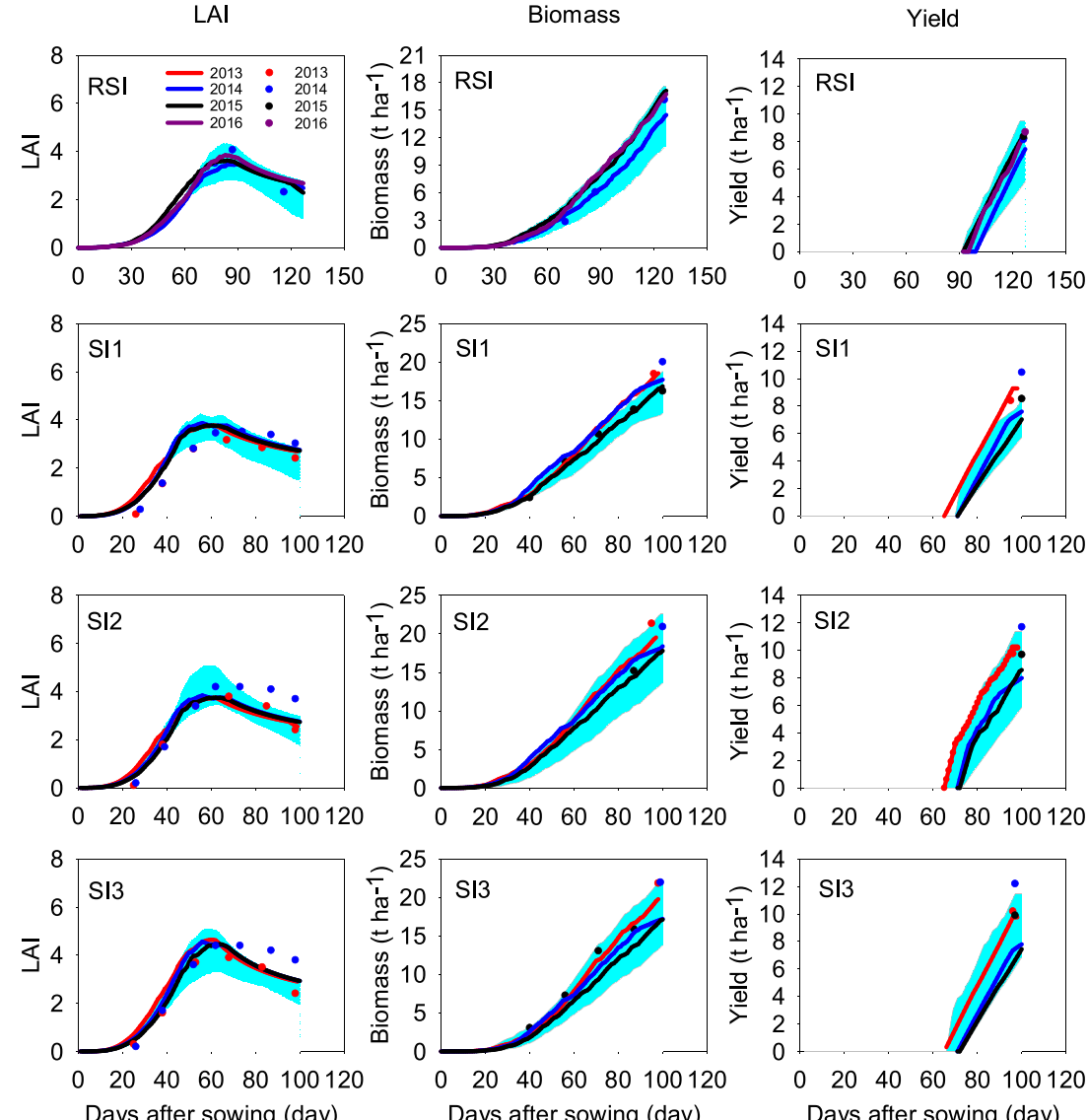

Days after sowing (day)
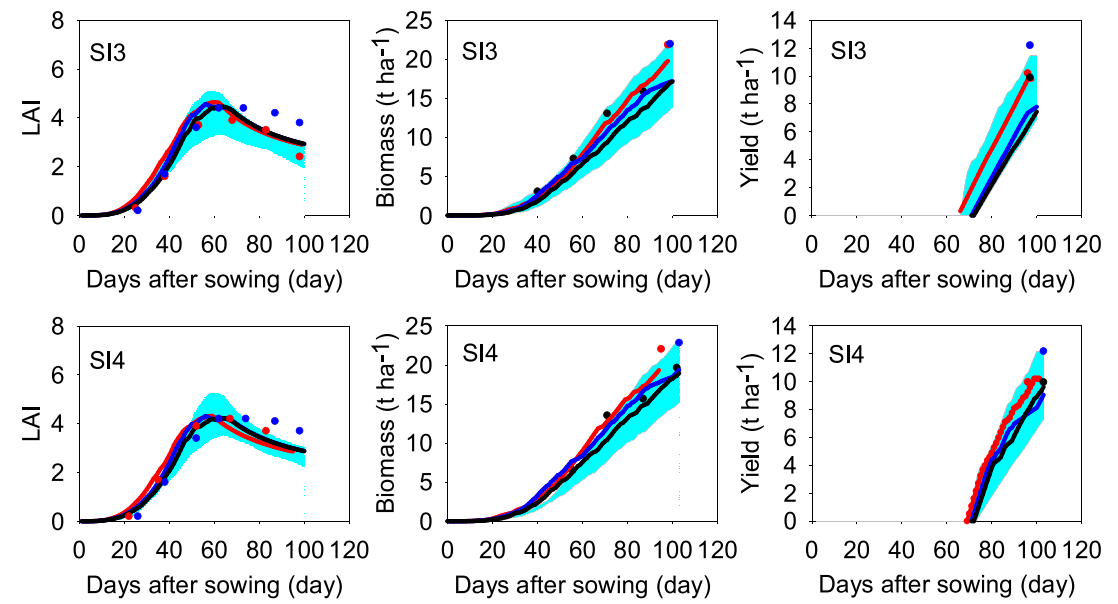

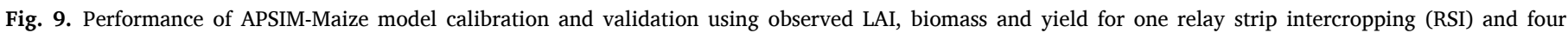

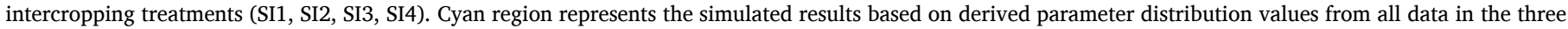

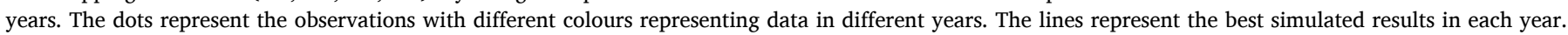

Oort et al., 2020; Wang et al., 2019, 2015; Gou et al., 2017b; Liu et al., 2018). However, light interception is only one component of the whole model. In order to achieve satisfactory simulation of crop light capture, biomass growth and grain yields, changes in key model parameters to account for changes in crop physiology and canopy microclimate in the strip intercropping systems are also needed, as demonstrated by our results in this study.

Strip-intercropping systems often out-yields mono-cropping systems mainly due to increased biomass and yield in the border rows of the dominant species as a result of greater radiation interception (Wang et al., 2017; Zhu et al., 2020). The newly implemented model simulates light interception of intercrops in response to their crop strip widths that determine the border row fractions in the system. In the maize-soybean strip intercropping system as an example, smaller crop strips will create a larger fraction of border rows, which will increase the light interception of the taller crop maize while decrease the light interception of soybean (Fig. 5), potentially leading to higher maize biomass and yield. In that regard, the new model captures the border row effect, while the default model in APSIM does not. This enhanced ability to simulate effect of border rows is demonstrated here (Fig. 5) and also by Gou et al. (2017a).
In addition to border-row effect, changes in morphology and physiology of the shorter intercrop under shade warrant further study for improved modelling of intercropping systems (see section below). However, direct measurements of light interception and physiological responses of component crops with varying row configurations are expensive and not always economically or experimentally feasible (Knörzer et al., 2011). Efforts to improve modelling of intercrops like the current study will always play an essential role in future studies.

\subsection{Parametrisation for soybean and maize modelling under strip intercropping}

With the strip intercrop light interception model and average values of key parameters from four configuration of strip-intercropping, our results show that the model was not able to correctly simulate biomass and grain yield of the two crops across different treatments of row configurations. Key parameters like RUE and extinction coefficient etc. change with row configurations, consistent to findings in previous studies (Liu et al., 2017b; Wang et al., 2015). The much greater changes in parameters for the shorter soybean crop than for the higher maize crop imply the need for re-parameterising the crops in strip 

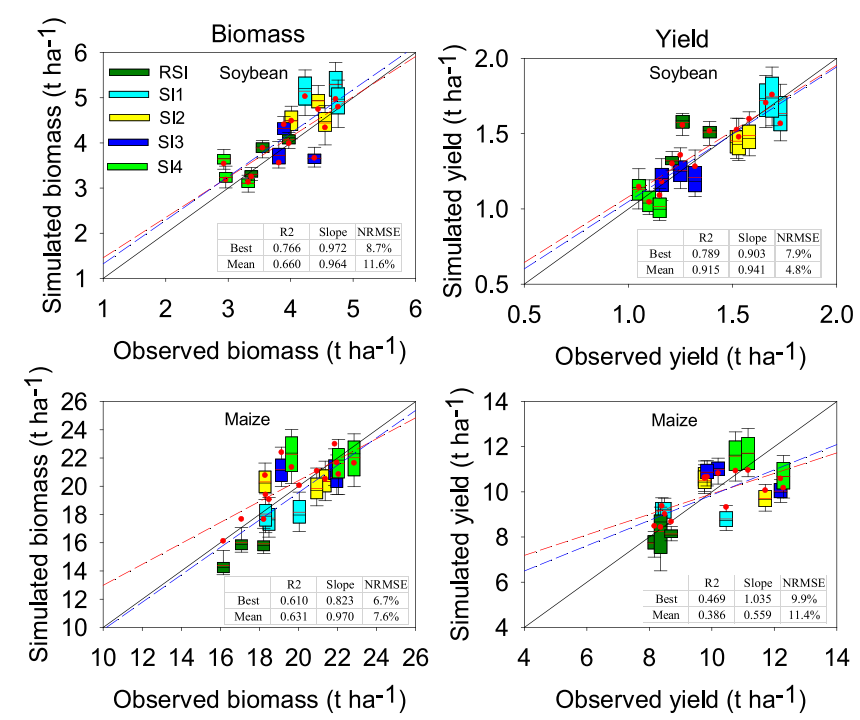

Fig. 10. Comparison of observed and simulated final biomass and yield for model evaluation with the derived ensembles of parameters distribution. The red circles show the best validation results (the least NRMSE of validation data) obtained with the ensembles of parameters. The black horizontal lines of the box plot indicate the $10,25,50,75$, and 90 percentiles of simulated values and the red horizontal line show the average. The blue and red dashed lines indicate the regression lines of the best and mean simulation results, respectively (For interpretation of the references to colour in this figure legend, the reader is referred to the web version of this article.).

intercropping, particularly the shorter crop. The optimisation approach used in this study enabled to derive parameter sets for overall good simulations of intercrops across all treatments, demonstrating the usefulness of this approach in future studies, particularly for complex systems like strip-intercropping.

Plasticity in crop traits is an important factor contributing to changes in canopy structure and light capture in strip intercropping (Zhu et al., 2015). During the co-growth period of maize and soybean crops, the shorter soybean crop experiences a shade environment with decreased light intensity and decreased red and far red ratio (Liu et al., 2017a; Yang et al., 2014). This shade environment causes changes in leaf size, node appearance rate, plant height and radiation use efficiency of soybean (Liu et al., 2017a; Li et al., 2020a, 2020b). We think that these changes are the key causes of changes in model parameters across treatments and from those for mono-crops, e.g., the higher RUE, specific leaf area, lower extinction coefficient and lower stem weight per unit height of soybean under increased shading, and the slower thermal time to senesce one node $\left(118.8^{\circ} \mathrm{C} \mathrm{d}\right.$ /node $)$ of soybean in strip intercropping treatments as compared to that of APSIM default $\left(68^{\circ} \mathrm{C} \mathrm{d} /\right.$ node) and in other studies (Archontoulis et al., 2020).

The taller crop, on the other hand, will be more exposed to radiation because of the border row effects. The extent of such changes will likely depend on the row configuration and relative heights of the two crops, consequently impacting on the RUE and $k$. The higher RUE value derived for maize in this study could be due to two main reasons: 1) modern cultivars utilise light better, 2) border-row effect, leading to similar yield of maize in strip-intercropping to that of mono-maize despite half planting area.

\subsection{Future steps}

In China, the main limitations to the development of intercropping systems are the increase in labor costs and a shift of rural labour into the construction and industrial sectors (Feike et al., 2012). The authorities promote therefore a transition from traditional row-intercropping systems to wide strip intercropping systems that can be more easily mechanized. This requires a modelling tool to help design the best row-spacing and configurations for such strip-intercropping across different climatic regions so that machineries can also be designed. In this study, APSIM with the new strip-intercrops light interception model and Bayesian calibration method appeared to be an effective means to simulate the productivity of such intercropping system and to assist in the design of row configurations, even though more work needs to be done for estimation of key model parameters appropriate for a new configuration.

Further model improvements will include better capturing the plasticity of the intercrops, especially the lower crops like soybean, in response to the change caused by different row configuration and how this impacts the key model parameters like RUE, extinction coefficients, leaf and stem growth. Future advance will benefit significantly from experimental data for intercrops as compared to mono-crops on: 1) individual leaf size and leaf/node stages, 2) dynamics of developments, plant height, LAI and biomass, 3) partition of biomass to organs (leaf, stem, head), and 4) grain growth and yield. In addition, changes in belowground root traits (rooting depth, root length/mass distributions in soil etc.) of intercrops can't be ignored for better understanding the competition in water and nutrients resources in soil, although data on this aspect is even more difficult to get. It remains relatively unexplored how configuration with different crop species and strip width will change or enhance the root system development of intercrops and subsequently affect the utilisation of below ground resources. More experimental data are becoming available for such model improvement (Liu et al., 2017a, 2018), but new modelling efforts need to catch up. Model improvement will also include new parameterisation or update for modern crop cultivars, and better quantification of how intercropping change physiological traits from mono-crops.

\section{Conclusions}

This was the first attempt to integrate a strip-intercrop light interception model into APSIM, to allow evaluation of how planting configurations influence light interception, plant growth and grain yield in strip intercropping. A quasi-Bayesian optimisation approach enabled to derive the key model parameters by constraining the model to LAI, biomass and yield of strip-planted maize and soybean crops. These key model parameters were found to change with row configuration, indicating a need to improve modelling morphology and physiology of intercrops. The improved model improved the simulation of biomass and grain yield of soybean and maize crops across row configuration treatments, and can be potentially used to evaluate impact of planting configurations on productivity of strip intercropping systems.

\section{Declaration of Competing Interest}

The authors report no declarations of interest.

\section{Acknowledgements}

This study was supported by National Natural Science Foundation of China (nos. 32001416), by CSIRO and Chinese Academy of Agricultural Sciences (CAAS) through the research project 'Scientific benchmarks for sustainable agricultural intensification', and China Scholarship Council (CSC) under the CSIRO-Chinese Ministry of Education (MoE) PhD Fellowship Research Program.

\section{Appendix A. Supplementary data}

Supplementary material related to this article can be found, in the online version, at doi:https://doi.org/10.1016/j.fcr.2021.108122. 


\section{References}

Angstrom, A., 1924. Solar and terrestrial radiation. Report to the international commission for solar research on actinometric investigations of solar and atmospheric radiation. Q. J. R. Meteorol. Soc. 50 (210), 121-126.

Archontoulis, S.V., Miguez, F.E., Moore, K.J., 2014. Evaluating APSIM maize, soil water, soil nitrogen, manure, and soil temperature modules in the Midwestern United States. Agron. J. 106 (3), 1025-1040.

Archontoulis, S.V., Castellano, M.J., Licht, M.A., Nichols, V., Baum, M., Huber, I., Martinez-Feria, R., Puntel, L., Ordóñez, R.A., Iqbal, J., Wright, E.E., Dietzel, R.N., Helmers, M., Vanloocke, A., Liebman, M., Hatfield, J.L., Herzmann, D., Córdova, S. C., Edmonds, P., Togliatti, K., Kessler, A., Danalatos, G., Pasley, H., Pederson, C., Lamkey, K.R., 2020. Predicting crop yields and soil-plant nitrogen dynamics in the US Corn Belt. Crop Sci. 60 (2), 721-738.

Banik, P., Midya, A., Sarkar, B.K., Ghose, S.S., 2006. Wheat and chickpea intercropping systems in an additive series experiment: advantages and weed smothering. Eur. J. Agron. 24 (4), 325-332.

Baumann, D., Bastiaans, L., Goudriaan, J., Van Laar, H., Kropff, M., 2002. Analysing crop yield and plant quality in an intercropping system using an eco-physiological mode for interplant competition. Agric. Sys. 73 (2), 173-203.

Berghuijs, H.N.C., Wang, Z., Stomph, T.J., Weih, M., Van der Werf, W., Vico, G., 2020. Identification of species traits enhancing yield in wheat-faba bean intercropping: development and sensitivity analysis of a minimalist mixture model. Plant Soil 455 (1), 203-226.

Berghuijs, H.N.C., Weih, M., van der Werf, W., Karley, A.J., Adam, E., VillegasFernández, Á.M., Kiær, L.P., Newton, A.C., Scherber, C., Tavoletti, S., Vico, G., 2021 Calibrating and testing APSIM for wheat-faba bean pure cultures and intercrops across Europe. Field Crops Res. 264, 108088.

Brooker, R.W., Bennett, A.E., Cong, W.-F., Daniell, T.J., George, T.S., Hallett, P.D., Hawes, C., Iannetta, P.P.M., Jones, H.G., Karley, A.J., Li, L., McKenzie, B.M., Pakeman, R.J., Paterson, E., Schöb, C., Shen, J., Squire, G., Watson, C.A., Zhang, C., Zhang, F., Zhang, J., White, P.J., 2015. Improving intercropping: a synthesis of research in agronomy, plant physiology and ecology. New Phytol. 206 (1), 107-117.

Carberry, P., Adiku, S., McCown, R., Keating, B., 1996. Application of the APSIM Cropping Systems Model to Intercropping Systems.

Chen, P., Du, Q., Liu, X., Zhou, L., Hussain, S., Lei, L., Song, C., Wang, X., Liu, W., Yang, F., 2017. Effects of reduced nitrogen inputs on crop yield and nitrogen use efficiency in a long-term maize-soybean relay strip intercropping system. PLoS One 12 (9), e0184503.

Chimonyo, V.G.P., Modi, A.T., Mabhaudhi, T., 2016. Simulating yield and water use of a sorghum-cowpea intercrop using APSIM. Agric. Water Manag. 177, 317-328.

Cong, W.F., Hoffland, E., Li, L., Six, J., Sun, J.H., Bao, X.G., Zhang, F.S., Werf, W.V.D., 2015. Intercropping enhances soil carbon and nitrogen. Glob. Change Biol. 21 (4), $1715-1726$.

Corre-Hellou, G., Faure, M., Launay, M., Brisson, N., Crozat, Y., 2009. Adaptation of the STICS intercrop model to simulate crop growth and $\mathrm{N}$ accumulation in pea-barley intercrops. Field Crops Res. 113 (1), 72-81.

Dimes, J., Achien, J., Mesfin, T., Abeya, T., Makoko, B., Nhantumbo, N., Rodriguez, D., 2011. Evaluation of APSIM to simulate maize-bean cropping systems in eastern and southern Africa: an alternative approach. 5th World Congress on Conservation Agriculture and Farming Systems Design Australian Centre for International Agricultural Research 1-4.

Echarte, L., Maggiora, A.D., Cerrudo, D., Gonzalez, V.H., Abbate, P., Cerrudo, A., Sadras, V.O., Calviño, P., 2011. Yield response to plant density of maize and sunflower intercropped with soybean. Field Crops Res. 121 (3), 423-429.

Fan, F., Zhang, F., Song, Y., Sun, J., Bao, X., Guo, T., Li, L., 2006. Nitrogen fixation of Faba bean (Vicia faba L.) interacting with a non-legume in two contrasting intercropping systems. Plant Soil 283 (1), 275-286.

Fehr, W.R., Caviness, C.E., 1977. Stages of Soybean Development. Iowa State University of Science and Technology Ames, Iowa.

Feike, T., Doluschitz, R., Chen, Q., Graeff-Hönninger, S., Claupein, W., 2012. How to overcome the slow death of intercropping in the North China Plain. SustainabilityBasel 4 (10), 2550-2565.

Francis, C.A., 1989. Biological efficiencies in multiple-cropping systems. Adv. Agron. 42 $1-42$.

Gao, Y., Duan, A., Qiu, X., Liu, Z., Sun, J., Zhang, J., Wang, H., 2010a. Distribution of roots and root length density in a maize/soybean strip intercropping system. Agric. Water Manag. 98 (1), 199-212.

Gao, Y., Duan, A., Qiu, X., Sun, J., Zhang, J., Liu, H., Wang, H., 2010b. Distribution and use efficiency of photosynthetically active radiation in strip intercropping of maize and soybean. Agron. J. 102 (4), 1149-1157.

Ghosh, P., Tripathi, A., Bandyopadhyay, K., Manna, M., 2009. Assessment of nutrient competition and nutrient requirement in soybean/sorghum intercropping system. Eur. J. Agron. 31 (1), 43-50.

Gou, F., van Ittersum, M.K., Simon, E., Leffelaar, P.A., van der Putten, P.E.L., Zhang, L. van der Werf, W., 2017a. Intercropping wheat and maize increases total radiation interception and wheat RUE but lowers maize RUE. Eur. J. Agron. 84, 125-139.

Gou, F., van Ittersum, M.K., van der Werf, W., 2017b. Simulating potential growth in a relay-strip intercropping system: model description, calibration and testing. Field Crops Res. 200, 122-142.

Goudriaan, J., 1977. Crop Micrometeorology: a Simulation Study. Pudoc.

He, D., Wang, E., Wang, J., Lilley, J., Luo, Z., Pan, X., Pan, Z., Yang, N., 2017. Uncertainty in canola phenology modelling induced by cultivar parameterization and its impact on simulated yield. Agr Forest Meteorol 232, 163-175.

Holzworth, D.P., Huth, N.I., deVoil, P.G., Zurcher, E.J., Herrmann, N.I., McLean, G., Chenu, K., van Oosterom, E.J., Snow, V., Murphy, C., Moore, A.D., Brown, H.,
Whish, J.P.M., Verrall, S., Fainges, J., Bell, L.W., Peake, A.S., Poulton, P.L., Hochman, Z., Thorburn, P.J., Gaydon, D.S., Dalgliesh, N.P., Rodriguez, D., Cox, H., Chapman, S., Doherty, A., Teixeira, E., Sharp, J., Cichota, R., Vogeler, I., Li, F.Y., Wang, E., Hammer, G.L., Robertson, M.J., Dimes, J.P., Whitbread, A.M., Hunt, J., van Rees, H., McClelland, T., Carberry, P.S., Hargreaves, J.N.G., MacLeod, N., McDonald, C., Harsdorf, J., Wedgwood, S., Keating, B.A., 2014. APSIM - evolution towards a new generation of agricultural systems simulation. Environ. Model. Softw. $62,327-350$.

Keating, B., Carberry, P., 1993. Resource capture and use in intercropping: solar radiation. Field Crops Res. 34 (3-4), 273-301.

Keating, B.A., Carberry, P.S., Hammer, G.L., Probert, M.E., Robertson, M.J., Holzworth, D., Huth, N.I., Hargreaves, J.N., Meinke, H., Hochman, Z., 2003. An overview of APSIM, a model designed for farming systems simulation. Eur. J. Agron. 18 (3-4), 267-288.

Kirkegaard, J., Hunt, J., McBeath, T., Lilley, J., Moore, A., Verburg, K., Robertson, M., Oliver, Y., Ward, P., Milroy, S., 2014. Improving water productivity in the Australian Grains industry — a nationally coordinated approach. Crop Pasture Sci. 65 (7), 583-601.

Knörzer, H., Grözinger, H., Graeff-Hönninger, S., Hartung, K., Piepho, H.P., Claupein, W., 2011. Integrating a simple shading algorithm into CERES-wheat and CERES-maize with particular regard to a changing microclimate within a relay-intercropping system. Field Crops Res. 121 (2), 274-285.

Kropff, M.J., Van Laar, H., 1993. Modelling crop-weed interactions. Int. Rice Res. Inst.

Li, L., Sun, J., Zhang, F., Li, X., Rengel, Z., Yang, S., 2001. Wheat/maize or wheat/ soybean strip intercropping: II. Recovery or compensation of maize and soybean after wheat harvesting. Field Crops Res. 71 (3), 173-181.

Li, C., Hoffland, E., Kuyper, T.W., Yu, Y., Zhang, C., Li, H., Zhang, F., van der Werf, W., 2020a. Syndromes of production in intercropping impact yield gains. Nat. Plants 6 (6), 653-660.

Li, S., Evers, J.B., van der Werf, W., Wang, R., Xu, Z., Guo, Y., Li, B., Ma, Y., 2020b. Plant architectural responses in simultaneous maize/soybean strip intercropping do not lead to a yield advantage. Ann. Appl. Biol. 177 (2), 195-210.

Liu, L., Zhu, Y., Tang, L., Cao, W., Wang, E., 2013a. Impacts of climate changes, soil nutrients, variety types and management practices on rice yield in East China: a case study in the Taihu region. Field Crops Res. 149, 40-48.

Liu, Z., Hubbard, K.G., Lin, X., Yang, X., 2013b. Negative effects of climate warming on maize yield are reversed by the changing of sowing date and cultivar selection in Northeast China. Glob. Change Biol. 19 (11), 3481-3492.

Liu, X., Rahman, T., Song, C., Su, B., Yang, F., Yong, T., Wu, Y., Zhang, C., Yang, W., 2017a. Changes in light environment, morphology, growth and yield of soybean in maize-soybean intercropping systems. Field Crops Res. 200, 38-46.

Liu, X., Rahman, T., Yang, F., Song, C., Yong, T., Liu, J., Zhang, C., Yang, W., 2017b. PAR interception and utilization in different maize and soybean intercropping patterns. PLoS One 12 (1), e0169218.

Liu, X., Rahman, T., Song, C., Yang, F., Su, B., Cui, L., Bu, W., Yang, W., 2018. Relationships among light distribution, radiation use efficiency and land equivalent ratio in maize-soybean strip intercropping. Field Crops Res. 224, 91-101.

Luo, Z., Wang, E., Zheng, H., Baldock, J., Sun, O., Shao, Q., 2015. Convergent modelling of past soil organic carbon stocks but divergent projections. Biogeosciences 12 (14), 4373-4383.

Malone, R.W., Huth, N., Carberry, P.S., Ma, L., Kaspar, T.C., Karlen, D.L., Meade, T., Kanwar, R.S., Heilman, P., 2007. Evaluating and predicting agricultural management effects under tile drainage using modified APSIM. Geoderma 140 (3), 310-322.

Mao, L.-1., Zhang, L.-Z., Zhang, S.-p., Evers, J.B., van der Werf, W., Wang, J.-j., Sun, H.-q., Su, Z.-c., Spiertz, H., 2015. Resource use efficiency, ecological intensification and sustainability of intercropping systems. J. Integr. Agr 14 (8), 1542-1550.

Mohanty, M., Probert, M.E., Reddy, K.S., Dalal, R.C., Mishra, A.K., Subba Rao, A., Singh, M., Menzies, N.W., 2012. Simulating soybean-wheat cropping system: APSIM model parameterization and validation. Agric. Ecosyst. Environ. 152, 68-78.

Nelson, R.A., Cramb, R.A., 1998. Economic incentives for farmers in the Philippine uplands to adopt hedgerow intercropping. J. Environ. Manag. 54 (2), 83-100.

Pembleton, K.G., Rawnsley, R.P., Jacobs, J.L., Mickan, F.J., O'Brien, G.N., Cullen, B.R., Ramilan, T., 2013. Evaluating the accuracy of the Agricultural Production Systems Simulator (APSIM) simulating growth, development, and herbage nutritive characteristics of forage crops grown in the south-eastern dairy regions of Australia. Crop Pasture Sci. 64 (2), 147-164.

Pronk, A., Goudriaan, J., Stilma, E., Challa, H., 2003. A simple method to estimate radiation interception by nursery stock conifers: a case study of eastern white cedar. Njas-Wagen J Life Sc 51 (3), 279-295.

Robertson, M., Carberry, P., 1998. Simulating growth and development of soybean in APSIM. In: Soybean's Role in Australia; Proceedings, 10th Australian Soybean Conference. 15-17 September 1998, Brisbane (53), pp. 130-136.

Robertson, M., Carberry, P., Huth, N., Turpin, J., Probert, M.E., Poulton, P., Bell, M., Wright, G., Yeates, S., Brinsmead, R., 2002. Simulation of growth and development of diverse legume species in APSIM. Aust. J. Agric. Res. 53 (4), 429-446.

Robertson, M., Gaydon, D., Latta, R., Peoples, M., Swan, A., 2004. Simulating lucerne/ crop companion farming systems in Australia. Proceedings of the 4th International Crop Science Congress'.(Australian Society of Agronomy: Brisbane, Qld).

Sun, H., Zhang, X., Wang, E., Chen, S., Shao, L., Qin, W., 2016. Assessing the contribution of weather and management to the annual yield variation of summer maize using APSIM in the North China Plain. Field Crops Res. 194, 94-102.

Tan, M., Gou, F., Stomph, T.J., Wang, J., Yin, W., Zhang, L., Chai, Q., van der Werf, W., 2020. Dynamic process-based modelling of crop growth and competitive water extraction in relay strip intercropping: model development and application to wheatmaize intercropping. Field Crops Res. 246, 107613. 
Thorburn, P.J., Probert, M.E., Robertson, F.A., 2001. Modelling decomposition of sugar cane surface residues with APSIM-Residue. Field Crops Res. 70 (3), 223-232.

Tsubo, M., Walker, S., 2002. A model of radiation interception and use by a maize-bean intercrop canopy. Agr. Forest Meteorol. 110 (3), 203-215.

Tsubo, M., Walker, S., Ogindo, H.O., 2005. A simulation model of cereal-legume intercropping systems for semi-arid regions: I. Model development. Field Crops Res. 93 (1), 10-22.

van Oort, P., Gou, F., Stomph, T., van der Werf, W., 2020. Effects of strip width on yields in relay-strip intercropping: a simulation study. Eur. J. Agron. 112, 125936.

Wang, E., Robertson, M.J., Hammer, G.L., Carberry, P.S., Holzworth, D., Meinke, H., Chapman, S.C., Hargreaves, J.N.G., Huth, N.I., McLean, G., 2002. Development of a generic crop model template in the cropping system model APSIM. Eur. J. Agron. 18 (1), 121-140

Wang, E., Cresswell, H., Yu, Q., Verburg, K., 2008. Summer forage cropping as an effective way to control deep drainage in south-eastern Australia - a simulation study. Agric. Ecosyst. Environ. 125 (1-4), 127-136.

Wang, Z., Zhao, X., Wu, P., He, J., Chen, X., Gao, Y., Cao, X., 2015. Radiation interception and utilization by wheat/maize strip intercropping systems. Agr Forest Meteorol 204, 58-66.

Wang, X., Deng, X., Pu, T., Song, C., Yong, T., Yang, F., Sun, X., Liu, W., Yan, Y., Du, J., Liu, J., Su, K., Yang, W., 2017a. Contribution of interspecific interactions and phosphorus application to increasing soil phosphorus availability in relay intercropping systems. Field Crops Res. 204, 12-22.

Wang, Z., Zhao, X., Wu, P., Gao, Y., Yang, Q., Shen, Y., 2017b. Border row effects on light interception in wheat/maize strip intercropping systems. Field Crops Res. 214, 1-13.

Wang, N., Wang, E., Wang, J., Zhang, J., Zheng, B., Huang, Y., Tan, M., 2018. Modelling maize phenology, biomass growth and yield under contrasting temperature conditions. Agr Forest Meteorol 250, 319-329.

Wang, Z., Cao, Q., Shen, Y., 2019. Modeling light availability for crop strips planted within apple orchard. Agric. Sys. 170, 28-38.

Wiles, L., Wilkerson, G., 1991. Modeling competition for light between soybean and broadleaf weeds. Agric. Sys. 35 (1), 37-51.

Wu, Y., Yang, F., Gong, W., Ahmed, S., Fan, Y., Wu, X., Yong, T., Liu, W., Shu, K., Liu, J., Du, J., Yang, W., 2017. Shade adaptive response and yield analysis of different soybean genotypes in relay intercropping systems. J. Integr. Agr 16 (6), 1331-1340.

Yang, X., Asseng, S., Wong, M.T.F., Yu, Q., Li, J., Liu, E., 2013. Quantifying the interactive impacts of global dimming and warming on wheat yield and water use in China. Agr Forest Meteorol 182, 342-351.
Yang, F., Huang, S., Gao, R., Liu, W., Yong, T., Wang, X., Wu, X., Yang, W., 2014. Growth of soybean seedlings in relay strip intercropping systems in relation to light quantity and red:far-red ratio. Field Crops Res. 155 (0), 245-253.

Yang, X., Chen, F., Lin, X., Liu, Z., Zhang, H., Zhao, J., Li, K., Ye, Q., Li, Y., Lv, S., Yang, P., Wu, W., Li, Z., Lal, R., Tang, H., 2015. Potential benefits of climate change for crop productivity in China. Agr Forest Meteorol 208, 76-84.

Yang, F., Liao, D., Wu, X., Gao, R., Fan, Y., Raza, M.A., Wang, X., Yong, T., Liu, W., Liu, J., 2017. Effect of aboveground and belowground interactions on the intercrop yields in maize-soybean relay intercropping systems. Field Crops Res. 203, 16-23.

Yong, T.-W., Chen, P., Dong, Q., Du, Q., Yang, F., Wang, X.-c., Liu, W.-g., Yang, W.-y., 2018. Optimized nitrogen application methods to improve nitrogen use efficiency and nodule nitrogen fixation in a maize-soybean relay intercropping system. J. Integr. Agr 17 (3), 60345-60347.

Yu, Y., Stomph, T.-J., Makowski, D., van der Werf, W., 2015. Temporal niche differentiation increases the land equivalent ratio of annual intercrops: a metaanalysis. Field Crops Res. 184, 133-144.

Zeleke, K.T., 2017. Fallow management increases soil water and nitrogen storage. Agric. Water Manag. 186, 12-20.

Zhang, F., Li, L., 2003. Using competitive and facilitative interactions in intercropping systems enhances crop productivity and nutrient-use efficiency. Plant Soil 305-312. Springer.

Zhang, L., van der Werf, W., Bastiaans, L., Zhang, S., Li, B., Spiertz, J.H.J., 2008. Light interception and utilization in relay intercrops of wheat and cotton. Field Crops Res. 107 (1), 29-42.

Zhao, Z., Qin, X., Wang, E., Carberry, P., Zhang, Y., Zhou, S., Zhang, X., Hu, C., Wang, Z., 2015. Modelling to increase the eco-efficiency of a wheat-maize double cropping system. Agric. Ecosyst. Environ. 210, 36-46.

Zhen, X., Shao, H., Zhang, W., Huo, W., Batchelor, W.D., Hou, P., Wang, E., Mi, G., Miao, Y., Li, H., 2018. Testing a bell-shaped function for estimation of fully expanded leaf area in modern maize under potential production conditions. Crop J. 6 (5), 527-537.

Zhu, J., van der Werf, W., Anten, N.P., Vos, J., Evers, J.B., 2015. The contribution of phenotypic plasticity to complementary light capture in plant mixtures. New Phytol. 207 (4), 1213-1222.

Zhu, B., Liu, F., Xie, Z., Guo, Y., Li, B., Ma, Y., 2020. Quantification of light interception within image-based 3-D reconstruction of sole and intercropped canopies over the entire growth season. Ann. Bot. - London 126 (4), 701-712. 